\title{
Astrocyte Signaling Gates Long-Term Depression at Corticostriatal Synapses of the Direct Pathway
}

\author{
Anna Cavaccini, ${ }^{1 \star}$ Caitlin Durkee, ${ }^{2 \star}$ Paulo Kofuji, ${ }^{2}$ Raffaella Tonini, ${ }^{1 \dagger}$ and Alfonso Araque ${ }^{2 \dagger}$ \\ ${ }^{1}$ Neuromodulation of Cortical and Subcortical Circuits Laboratory, Neuroscience Area, Istituto Italiano di Tecnologia, Genova 16163, Italy, and \\ ${ }^{2}$ Department of Neuroscience, University of Minnesota, Minneapolis, Minnesota 55455
}

\begin{abstract}
Despite extensive research into understanding synaptic mechanisms of striatal plasticity, the functional role played by astrocytes in this region remains to be fully elucidated. It was recently demonstrated that high-frequency stimulation (HFS) of cortical inputs induced long-term depression (LTD) mediated by adenosine A1 receptor (A1R) activation at corticostriatal synapses of the direct pathway [cortico-striatal projection neuron (dSPN)] in the dorsolateral striatum (DLS). Because astrocyte-derived adenosine has been shown to regulate synaptic transmission in several brain areas, we investigated whether this form of neuron-astrocyte signaling contributes to synaptic plasticity in the DLS of male and female mice. We found that cortical HFS increases calcium $\left(\mathrm{Ca}^{2+}\right)$ levels in striatal astrocytes through activation of metabotropic glutamate receptor type 5 (mGluR5) signaling and that this astrocyte-mediated response is necessary for A1R-mediated LTD. Consistent with this, astrocyte activation with $\mathrm{G}_{\mathrm{q}}$ designer receptors exclusively activated by designer drugs (DREADDs) induced A1R-mediated synaptic depression at cortico-dSPN synapses. Together, these results indicate that astrocytes are integral elements of striatal A1Rmediated LTD.
\end{abstract}

Key words: astrocyte calcium signaling; astrocytes; long-term depression; striatal synaptic plasticity

\section{Significance Statement}

Abnormal striatal circuit function is implicated in several disorders such as Parkinson's disease and Huntington's disease. Thus, there is a need to better understand the mechanisms supporting proper striatal activity. While extensive work has revealed the many important contributions from neurons in striatal function, far less is known about the role of astrocytes in this brain area. We show that long-term depression (LTD) at corticostriatal synapses of the direct pathway is not strictly a neuronal phenomenon; astrocytes respond to corticostriatal stimulation and this astrocyte response is necessary for LTD. This research adds to the accumulating evidence that astrocytes are active and integral players in synaptic communication, and that neuron-astrocyte interactions are key cellular processes involved in brain function.

Received Oct. 2, 2019; revised May 4, 2020; accepted May 5, 2020.

Author contributions: A.C., C.D., R.T., and A.A. designed research; A.C., C.D., and P.K. performed research; A.C. and C.D. analyzed data; A.A., A.C., C.D., P.K., and R.T. wrote the paper.

${ }^{*}$ A.C. and C.D. are co-first authors.

${ }^{\dagger}$ R.T. and A.A. are co-senior authors.

This work was supported by the Fondazione Istituto Italiano di Tecnologia (R.T.), the Compagnia di San Paolo Grant 20130942 (to R.T.), the Fondazione Cariplo Grant 20130871 (to R.T.), the National Institutes of Health (NIH)-National Institute of Neurological Disorders and Stroke (NINDS) Grant R01NS097312 (to A.A.), the NIH-National Institute on Drug Abuse Grant R01DA048822 (to A.A.), and the NIH-NINDS Grant F31NS93751 (to C.D.). We thank Justin Lines for the CALSEE program for $\mathrm{Ca}^{2+}$ analysis; Kendrick Kay, Justin Lines, and Mario Martin-Fernandez for MATLAB and CALSEE assistance; Mark Sanders, Guillermo Marques, and Jason Mitchell at the University of Minnesota-University Imaging Centers for assistance using the Leica SP5 Multiphoton Confocal Upright Microscope; Alice Gino and Luca Nava at the Istituto Italiano di Tecnologia for technical assistance during immunohistochemistry and stereotaxic surgery; Ju Chen for generously donating the IP3R2 ${ }^{-1-}$ mice; and the University of North Carolina at Chapel Hill Vector Core for providing the DREADDs viruses. Viral vectors used in this study were prepared by the University of Minnesota Viral Vector and Cloning Core.

The authors declare no competing financial interests.

Correspondence should be addressed to Alfonso Araque at araque@umn.edu or Raffaella Tonini at raffaella. tonini@iit.it.

https://doi.org/10.1523/JNEUROSCI.2369-19.2020

Copyright $\odot 2020$ the authors

\section{Introduction}

Increasing evidence is producing a fundamental shift in our understanding of intercellular communication at synapses. Rather than exclusive neurotransmitter signaling between presynaptic and postsynaptic neurons, astrocytes can respond to synaptically-released neurotransmitters and release gliotransmitters that can influence synaptic transmission (Araque et al., 2014; Papouin et al., 2017). Such bidirectional signaling between neurons and astrocytes has been established in several brain areas (Araque et al., 2014), and recent studies have focused on the role of astrocytes in the striatum (Martín et al., 2015; Jiang et al., 2016; Khakh, 2019). However, the involvement of astrocytes on synaptic plasticity mechanisms in this brain area remains largely incomplete.

The striatum is the main input nucleus of the basal ganglia (Cox and Witten, 2019). The most abundant striatal cell subpopulations are the inhibitory GABAergic striatal projection neurons (SPNs) of the direct (dSPN) and indirect output pathway (iSPN). While dSPNs express the dopamine receptor type 1 
(D1R), iSPNs express dopamine receptor type 2 (D2R; Kreitzer and Malenka, 2008). The activity of SPNs strongly depends on the excitatory cortical and thalamic inputs, since SPNs are largely quiescent. Thus, striatal circuit output can be influenced by plastic changes at excitatory synapses, which consequently regulate action selection and initiation (Kravitz et al., 2012; Sippy et al., 2015; O’Hare et al., 2016). Appropriate motor control relies on proper coordination of direct and indirect SPN activity, as well as coordinated regulation of corticostriatal synaptic plasticity at the level of the dorsolateral striatum (DLS; Cui et al., 2013; Tecuapetla et al., 2014; Trusel et al., 2015).

Extensive work has identified key presynaptic mechanisms that cooperate with postsynaptic dopaminergic signaling to enable cell-type-specific forms of high-frequency stimulation-dependent long-term depression (HFS-LTD) at cortico-iSPN and cortico-dSPN synapses (Wang et al., 2006b; Adermark and Lovinger, 2007; Kreitzer and Malenka, 2007; Bagetta et al., 2011; Trusel et al., 2015; Wu et al., 2015; Augustin et al., 2018). We have previously shown that when plasticity is induced by cortical stimulation, HFS-LTD is governed by endocannabinoids (eCBs) at cortico-iSPN synapses, whereas this is done by adenosine at cortico-dSPN synapses through the activation of adenosine A1 receptor (A1R; Trusel et al., 2015; Spigolon et al., 2018). These forms of LTD are concurrently and oppositely regulated by postsynaptic dopaminergic signaling in iSPNs and dSPNs, downstream of D2R and D1R, respectively (Trusel et al., 2015; Wu et al., 2015; Spigolon et al., 2018). The loss of this concurrent and pathway-specific regulation of corticostriatal synaptic plasticity has motor implications in a mouse model of Parkinson's disease (Trusel et al., 2015). eCB-dependent corticostriatal plasticity has been widely studied. Indeed, it is well known that SPNs release eCBs that bind presynaptic cannabinoid receptor type 1 (CB1R) to suppress subsequent glutamate release from corticostriatal terminals (Kreitzer and Malenka, 2007). However, the mechanisms underlying adenosine-dependent LTD are not fully elucidated, in particular the source of adenosine. We hypothesized that astrocytes were the adenosine source, because they can release ATP that, after being hydrolyzed into adenosine, can influence synaptic transmission and plasticity at nearby synapses in other brain regions (Zhang et al., 2003; Pascual et al., 2005; Serrano et al., 2006; Chen et al., 2013; Covelo and Araque, 2018).

In this study, we aimed to elucidate the role of astrocytes in mediating adenosine-dependent-LTD at cortico-dSPN synapses in the DLS (Trusel et al., 2015). We found that DLS astrocytes respond to cortical HFS with $\mathrm{Ca}^{2+}$ increases through activation of metabotropic glutamate receptor type 5 (mGluR5) and inositol triphosphate type 2 receptors $\left(\mathrm{IP}_{3} \mathrm{R} 2 \mathrm{~s}\right)$. Blocking astrocyte activation prevented the HFS-induced LTD. Furthermore, directly and selectively activating astrocytes with $\mathrm{G}_{\mathrm{q}}$ designer receptors exclusively activated by designer drugs (DREADDs) resulted in a depression of cortico-dSPN synapses in an A1R-dependent manner. Taken together, these results are the first to indicate that astrocytes are an integral component of a form of long-term synaptic plasticity in the striatum. These results add to the accumulating evidence that neuron-astrocyte interactions at the tripartite synapse are necessary for proper brain function.

\section{Materials and Methods}

Experimental model and subject details

Experiments were performed on 4- to 12-week-old male and female mice of the following strains: C57BL/6J, Drd2-eGFP bacterial artificial chromosome (BAC) transgenic mice, Drd1-tdTomato BAC transgenic mice, and $\mathrm{IP}_{3} \mathrm{R}^{-1-}$ (Li et al., 2005). The animals were housed in a controlled environment, on a $12 \mathrm{~h}$ light/dark cycle, with unrestricted access to food and water. All procedures involving animals were conducted in accordance with the Animal Care and Use Committee at the University of Minnesota and the Italian Ministry of Health's directives (D.lgs 26/2014) regulating animal research.

\section{Stereotaxic surgery}

Four- to six-week-old mice were anesthetized with a ketamine $(100 \mathrm{mg} /$ $\mathrm{kg}) /$ xylazine $(10 \mathrm{mg} / \mathrm{kg})$ cocktail $(0.2 \mathrm{ml} / \mathrm{kg}$ body weight $)$ and underwent stereotaxic surgery of different viruses. To measure $\mathrm{Ca}^{2+}$ signaling in astrocytes, mice were injected with an adeno-associated virus containing cytosolic GCaMP6f expression (AAV5 pZac2.1 gfaABC1D-cyto-GCaMP6f from Baljit Khakh, Addgene plasmid \#52925; http://n2t.net/addgene:52925; RRID: Addgene 52925, Haustein et al., 2014). For chemogenetic activation of $\mathrm{G}_{\mathrm{q}}$ signaling in astrocytes, mice were injected with AAV8-GFAPhM3Dq-mCherry. For control DREADDs experiments, mice received injections of AAV8-GFAP-mCherry. Stereotaxic coordinates used for DLS injections were (relative to bregma in $\mathrm{mm}$ ) $+1.0 \mathrm{AP}, \pm 2.00 \mathrm{ML}$, and -3.15 DV. Experiments were performed two to six weeks after surgery. All DREADDs viruses were purchased from the UPenn Vector Core, while the plasmid to generate the AAV8-GFAP-mCherry was purchased from Addgene (Plasmid \#58909) and was generated by the University of Minnesota Viral Vector and Cloning Core.

\section{Slice preparation}

Mice were anesthetized with isoflurane and decapitated, and their brains were transferred to ice-cold artificial CSF (aCSF) containing $110 \mathrm{~mm}$ choline chloride, $2.5 \mathrm{~mm} \mathrm{KCl}, 1.25 \mathrm{~mm} \mathrm{NaH}_{2} \mathrm{PO}_{4}, 7 \mathrm{~mm} \mathrm{MgCl}_{2}, 0.5 \mathrm{~mm}$ $\mathrm{CaCl}_{2}, 25 \mathrm{~mm} \mathrm{NaHCO}_{3}, 25 \mathrm{~mm}$ D-glucose, and $11.6 \mathrm{~mm}$ ascorbic acid, saturated with $95 \% \mathrm{O}_{2}$ and $5 \% \mathrm{CO}_{2}$ for dissection. Horizontal slices ( $270 \mu \mathrm{m}$ thick) were prepared using a Vibratome 1000 slicer (Leica), then transferred to new aCSF containing $115 \mathrm{~mm} \mathrm{NaCl}, 3.5 \mathrm{~mm} \mathrm{KCl}, 1.2$ mM NaH${ }_{2} \mathrm{PO}_{4}, 1.3 \mathrm{~mm} \mathrm{MgCl}_{2}, 2 \mathrm{~mm} \mathrm{CaCl} 2,25 \mathrm{~mm} \mathrm{NaHCO}_{3}$, and $25 \mathrm{~mm}$ D-glucose, and aerated with $95 \% \mathrm{O}_{2}$ and $5 \% \mathrm{CO}_{2}$. After incubating for $20 \mathrm{~min}$ at $32^{\circ} \mathrm{C}$, slices were kept at $22-24^{\circ} \mathrm{C}$. During experiments, slices were continuously superfused with aCSF at a rate of $2 \mathrm{ml} / \mathrm{min}$ at $28^{\circ} \mathrm{C}$.

\section{Slice electrophysiology}

Whole-cell patch-clamp recordings were made on dSPN of the DLS in horizontal slices that preserved corticostriatal connections (Nazzaro et al., 2012; Trusel et al., 2015; Cavaccini et al., 2018; Spigolon et al., 2018). dSPNs in the DLS were visualized under infrared-differential interference contrast and were identified based on their morphologic, electrical properties, and also by the expression of adenosine $\mathrm{A} 2 \mathrm{~A}$ receptor (A2AR; for iSPN) and substance P (SP; for dSPN; Nazzaro et al., 2012; Trusel et al., 2015; Cavaccini et al., 2018; Spigolon et al., 2018). In some experiments, Drd2-eGFP and Drd1-tdTomato BAC mice were used for electrophysiology experiments, where only GFP-negative and tdTomatopositive cells, respectively, were selected for recording. Patch pipettes (3-4 $\mathrm{M} \Omega$ ) were filled with a solution containing $130 \mathrm{~mm} \mathrm{KMeSO} 4,5 \mathrm{~mm}$ $\mathrm{KCl}, 5 \mathrm{mM} \mathrm{NaCl}, 10 \mathrm{~mm}$ HEPES, $0.1 \mathrm{~mm}$ EGTA, $2 \mathrm{~mm} \mathrm{MgCl}_{2}, 0.05 \mathrm{~mm}$ $\mathrm{CaCl}_{2}, 2 \mathrm{~mm}$ Na2-ATP, and 0.4 mM Na3-GTP (pH 7.2-7.3; 280-290 $\mathrm{mOsm} / \mathrm{kg}$ ).

Data were acquired using a Multiclamp 700B amplifier controlled by pClamp 10 software (Molecular Device), filtered at $10 \mathrm{kHz}$ and sampled at $20 \mathrm{kHz}$ (Digidata 1322, Molecular Device). Alternatively, recordings were acquired using PC-ONE amplifiers (Dagan Instruments) controlled by pClamp 10 software (Molecular Device) and filtered at $1 \mathrm{kHz}$ (DigiData 1440A). All data are reported without corrections for liquid junction potentials. Data where the input resistance or the access resistance changed $>20 \%$ have been excluded.

$\mathrm{Ca}^{2+}$ imaging

$\mathrm{Ca}^{2+}$ levels in astrocytes were monitored by two-photon microscopy (Leica DM6000 CFS upright multiphoton microscope with a TCS SP5 MP laser). Astrocyte regions of interest (ROIs) were selected by a custom MATLAB program, which detected ROIs whose $\mathrm{Ca}^{2+}$ signal changed $>2$ SD from baseline. The ROI $\mathrm{Ca}^{2+}$ values were then fed into a second custom MATLAB program that identified a $\mathrm{Ca}^{2+}$ event when the $\mathrm{Ca}^{2+}$ 
trace surpassed a threshold that was based on the 25th and 50th percentiles of the entire $\mathrm{Ca}^{2+}$ trace. Our measurement of $\mathrm{Ca}^{2+}$ event probability was calculated as the number of $\mathrm{Ca}^{2+}$ elevations grouped in 10-s bins recorded from the astrocytes in the field of view, and mean values were obtained by averaging each different experiment. The trend toward increased $\mathrm{Ca}^{2+}$ event probability for all treatment groups, which perhaps resulted from non-specific cellular activation by prolonged light excitation, was not corrected. References to " $n$ " in the text correspond to the number of experiments performed for each condition.

\section{Immunohistochemistry}

Anesthetized mice were perfused through the left cardiac ventricle with $4 \%$ paraformaldehyde in $0.1 \mathrm{~m}$ PBS. The brains were removed, postfixed overnight with paraformaldehyde and cut into $100-\mu \mathrm{m}$ slices using a Leica VT 1000 S vibratome. Brain sections were then blocked with PBS containing $10 \%$ normal goat serum (NGS) or normal donkey serum (NDS) and $0.5 \%$ Triton X-100 and incubated for $48 \mathrm{~h}$ with the primary antibody diluted in blocking solution. Appropriate fluorochrome-labeled secondary antibodies (Jackson ImmunoResearch) were then incubated overnight and used for detection. Antibodies against glial fibrillary acidic protein (GFAP; catalog \#G9269, 1:500, Sigma-Aldrich or catalog \#MAB360, 1:500, Chemicon) were used as a marker for astrocytes. Antibodies against neuron-specific nuclear protein (NeuN, catalog \#MABN140, 1:500, Millipore or catalog \#MAB377, 1:200, Chemicon) were used as a marker for neurons. Antibodies against NG2 chondroitin sulfate proteoglycan (NG2; catalog \#AB5320, 1:500, Millipore) was used to identify NG2 glial cells. Antibodies against ionized calcium binding adaptor molecule 1 (Iba1; catalog \#019-19741, 1:500, Wako) were used to localize microglial cells. Antibodies against oligodendrocyte lineage transcription factor 2 (Olig2; catalog \#NP1-28667, Novus, 1:500) were used to label oligodendrocytes. An antibody against mCherry was used as a marker for DREADDs (catalog \#ab205402, 1:500, Abcam). Fluorescent-stained sections were mounted with Vectashield mounting medium (Vector Laboratories). The stained sections were visualized with an Olympus FluoView FV1000 upright confocal microscope and analyzed for colocalization of DREADDs and other cell markers using ImageJ software (NIH).

\section{Immunofluorescence: identification of $d S P N$ s and iSPNs}

To identify SPNs of the direct (dSPN) and indirect (iSPN) pathway, neurons were filled with Neurobiotin $(0.5 \mathrm{mg} / \mathrm{ml}$, Vector Laboratories) or biocytin $(0.5 \mathrm{mg} / \mathrm{ml}$, Sigma-Aldrich) during recordings and subsequently processed for immunostaining of the A2A receptor (marker of iSPNs) and SP (marker of dSPNs; Nazzaro et al., 2012; Trusel et al., 2015). After recording, slices were fixed with $4 \%$ paraformaldehyde in $0.1 \mathrm{M}$ phosphate buffer (0.1 M PB; pH 7.4) overnight at $4^{\circ} \mathrm{C}$ and then incubated in primary antibodies. Rabbit polyclonal antibody to A2A (1:250, Enzo Life Sciences) and rat monoclonal antibody to SP (1:200, Millipore) were diluted in $0.1 \mathrm{M}$ PB containing $0.3 \%$ Triton X-100. Sections were subsequently incubated with Alexa Fluor 647-conjugated or Alexa Fluor 488-conjugated secondary antibodies (1:200) and Alexa Fluor 568-conjugated streptavidin (1:1000, ThermoFisher Scientific), mounted on glass slides, and coverslipped with ProLong Gold antifade reagent (ThermoFisher Scientific). Images were acquired with an inverted Leica TCS SP5 AOBS TANDEM confocal microscope.

\section{Data analysis}

Excitatory postsynaptic current (EPSC) and potential (EPSP) amplitudes were normalized to the mean value of 5 min before HFS or Clozapine$\mathrm{N}$-Oxide (CNO) application, and baseline values were considered 5 min before the stimulus. The occurrence and magnitude of synaptic plasticity was evaluated by comparing the normalized EPSP or EPSC amplitudes recorded before and after HFS delivery (25-30 min post-HFS) or CNO application (last $4 \mathrm{~min}$ ). Time course plots were generated by averaging the peak amplitude of individual EPSPs or EPSCs in 1-min bins. Presynaptic or postsynaptic changes in EPSPs and EPSCs were assessed from their coefficient of variation (CV), which was calculated by the ratio of the SD and the mean EPSP or EPSC amplitude of the last $7 \mathrm{~min}$ before compared with the last $7 \mathrm{~min}$ after HFS delivery (Shen et al., 2008), and the parameter $\mathrm{CV}^{-2}$ was used.

\section{Experimental design and statistical analyses}

The overall goal of this study was to investigate the role of astrocytes in corticostriatal LTD. To this end, EPSPs or EPSCs were evoked by stimulation of the deep Layer $\mathrm{V}$ of the somatosensory cortex in the presence of the $\mathrm{GABA}_{\mathrm{A}}$ receptor antagonist gabazine $(10 \mu \mathrm{M})$ or picrotoxin $(50$ $\mu \mathrm{M})$ and acquired every $10 \mathrm{~s}$ (for more details, see above, Slice preparation and Slice electrophysiology). To induce HFS-LTD, $4 \times 1$-s long 100$\mathrm{Hz}$ trains were repeated every $10 \mathrm{~s}$. During the HFS protocol, the postsynaptic cell was depolarized from -80 to $-50 \mathrm{mV}$ to mimic corticallyinduced upstates (Fig. 1A). In addition to measuring the effects of HFS on corticostriatal plasticity, we also monitored $\mathrm{Ca}^{2+}$ activity in striatal astrocytes using a genetically-encoded $\mathrm{Ca}^{2+}$ indicator (for more details, see above, $\mathrm{Ca}^{2+}$ imaging). Several pharmacological agents were used to block various receptor subtypes to assess their effects both on LTD and astrocyte $\mathrm{Ca}^{2+}$. Additionally, Guanosine $5^{\prime}-[\beta$-thio $]$ diphosphate trilithium salt (GDP $\beta$ S; $10 \mu \mathrm{M}$ ) was used to block G protein-coupled receptor (GPCR) signaling in neurons or in astrocytes. It was added to the intracellular solution described above for neurons or to an intracellular solution specific for astrocytes containing the following: $100 \mathrm{~mm}$ KMeSO4, $50 \mathrm{~mm} \mathrm{KCl,} 10 \mathrm{~mm}$ HEPES-K, and 2 mм ATP-Na2 (pH 7.3 adjusted with $\mathrm{KOH}$; osmolality $280-290 \mathrm{mOsm} / \mathrm{l}$ ). To allow the GDP $\beta$ S to load into the neuron or into the astrocyte and its syncytium, the patched cells were filled for $20 \mathrm{~min}(\mathrm{~min}$ ) before starting the experiment. For patch-loaded astrocytes, the pipette was removed after $20 \mathrm{~min}$ and then the experiment on dSPNs was performed. To test the effect of directly activating astrocytes on corticostriatal synaptic plasticity, $10 \mu \mathrm{M}$ $\mathrm{CNO}$ was bath-applied to horizontal brain slices from mice injected with either AAV8-GFAP-hM3Dq-mCherry or AAV8-GFAP-mCherry as control.

Appropriate parametric statistics were used to test our hypotheses, unless data did not meet the assumptions of the intended parametric test (normality test), in which case, appropriate non-parametric tests were used. Data were analyzed by one-way repeated-measures ANOVA (RM1WA) or a Friedman test for comparisons within a group (GraphPad Prism 6 software). Post hoc analyses (Tukey's and Dunnet multiple comparison test against control) were only performed for ANOVAs with significant main effects. For comparisons of two groups, a paired $t$ test or Wilcoxon non-parametric test was used (GraphPad Prism 6 software). Statistical details of experiments are shown in results, figures, and figure legends. Data are expressed as mean \pm SEM.

\section{Data and code availability}

Source data that support the findings of this study are available from the corresponding author on reasonable request. Custom MATLAB code for analyses of astrocyte $\mathrm{Ca}^{2+}$ are available from the corresponding author on individual request.

\section{Results}

It has been shown that HFS of deep Layer $\mathrm{V}$ of somatosensory cortex induces LTD at cortico-dSPN synapses in the DLS that is dependent on A1R activation (Trusel et al., 2015). In this study, we sought to identify the mechanisms mediating this A1R-dependent LTD. Since activated astrocytes have been found in several brain regions to release ATP/adenosine (Zhang et al., 2003; Pascual et al., 2005; Serrano et al., 2006; Chen et al., 2013; Covelo and Araque, 2018), we aimed to test the hypothesis that DLS astrocytes are involved in mediating this A1R-dependent plasticity.

\section{Adenosine and glutamate gate HFS-LTD at cortico-dSPN synapses}

We recorded EPSPs or EPSCs evoked by stimulation of deep Layer $\mathrm{V}$ of the somatosensory cortex in dSPNs, identified by immunostaining for A2AR (for iSPN) and SP (for dSPN; Fig. 1A). After baseline recordings, we applied an HFS stimulation 
A
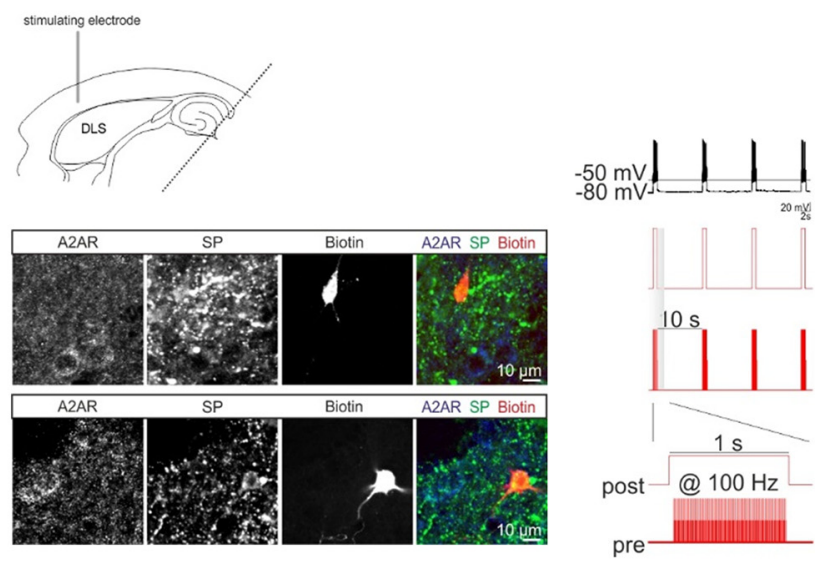

C

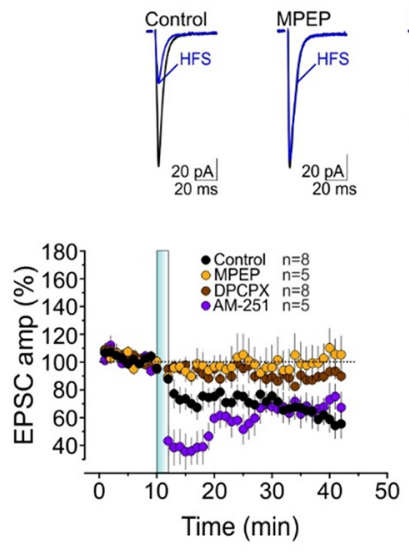

B

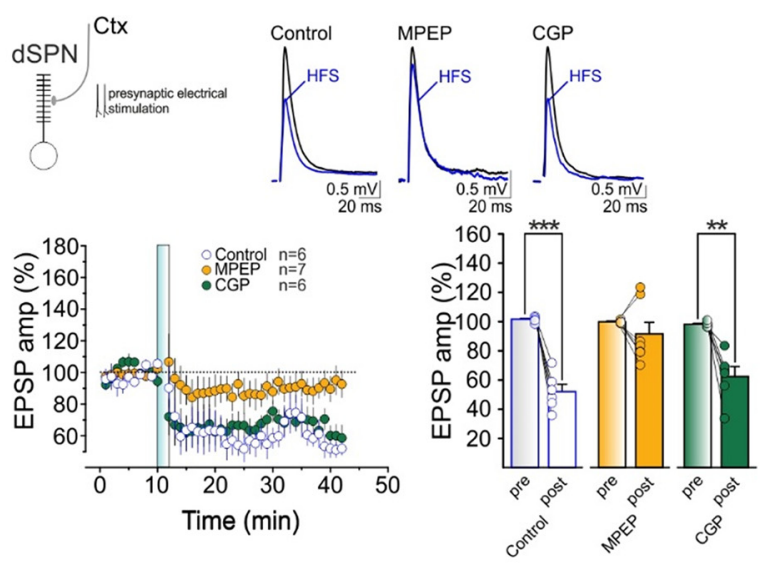

D

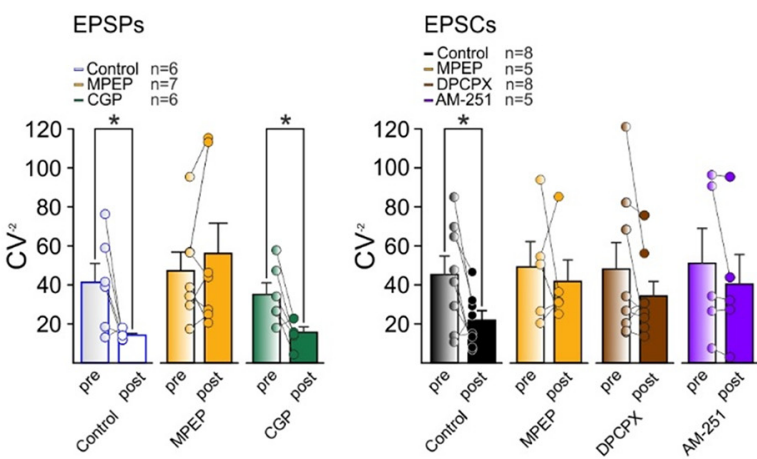

Figure 1. Adenosine and glutamate gate HFS-LTD at cortico-dSPN synapses. $A$, top left, Experimental configuration in horizontal brain slices of C57BL/6J mice. Bottom left, Confocal laser scanning microscope images of triple immunofluorescence for biotin, A2AR, and SP in patch-recorded neurons. Right, Scheme of HFS protocol. B, top left, Scheme showing glutamatergic cortical inputs to dSPNs, which are recruited following cortical electrical stimulation. Top right, Averaged recordings (10 EPSPS) before (black line) and after (blue line) HFS. Bottom left, Relative EPSP amplitude before and after HFS (vertical blue bar, as in other panels and figures) of cortical connections to dSPN in DLS in control conditions (white, $n=6,6$ mice), in the presence of the mGluR5 antagonist MPEP (yellow, $n=7,6$ mice), and in the presence of the GABA ${ }_{B} R$ antagonist, (GP55845 (green, $n=6,5$ mice). Bottom right, Mean normalized EPSP amplitudes before (pre) and 25-30 min after HFS (post; as in other figures) in control (white, $n=6,6$ mice, $t=9.3, \mathrm{df}=5,{ }^{* * *} p=0.0002$, paired $t$ test), MPEP (yellow, $n=7,6$ mice, $t=1, \mathrm{df}=6, p=0.3$, paired $t$ test), and (GP55845 (green, $n=6,5$ mice, $t=5, \mathrm{df}=5,{ }^{* *} p=0.0038$, paired $t$ test). C, top, Averaged recordings (10 EPSCs) before (black) and after (blue) HFS. Bottom left, Relative EPSP amplitude before and after HFS in control conditions (black, $n=8,7$ mice), in the presence of MPEP (yellow, $n=5,3$ mice), the A1R antagonist DPCPX (brown, $n=8,7$ mice), and the eCB CB1R antagonist AM-251 (purple, $n=5,3$ mice). Bottom right, Mean EPSC amplitudes before and after HFS in control (black, $n=8,7$ mice, $t=4.9, \mathrm{df}=7$, ${ }^{* *} p=0.0018$, paired $t$ test), MPEP (yellow, $n=5,3$ mice, $t=0.4, \mathrm{df}=4, p=0.7$, paired $t$ test), DPCPX (brown, $n=8,7$ mice, $t=2.2, \mathrm{df}=7, p=0.06$, paired $t$ test), or AM-251 (purple, $n=5,3$ mice, $t=2.8, \mathrm{df}=4,{ }^{*} p$ $=0.049$, paired $t$ test). D, left, Mean $\mathrm{CV}^{-2}$ before and after HFS for the EPSP group in control conditions (white, $n=6,6$ mice, $t=2.6, \mathrm{df}=5,{ }^{*} p=0.048$, paired $t$ test) or in the presence of MPEP (yellow, $n=7,6$ mice, $W=10, p=0.47$, Wilcoxon matched-pairs signed-rank test) or CGP (green, $n=6,5$ mice, $t=3.2, \mathrm{df}=5,{ }^{*} p=0.024$, paired $t$ test). Right, Mean CV ${ }^{-2}$ before and after HFS delivery for the EPSC group in control conditions (black, $n=8,7$ mice, $t=2.9, \mathrm{df}=7,{ }^{*} p=0.024$, paired $t$ test) or in the presence of MPEP (yellow, $n=5,3$ mice, $W=-1$, $p>0.9999$, Wilcoxon matched-pairs signed-rank test), DPCPX (brown, $n=8,7$ mice, $t=1.4, \mathrm{df}=7, p=0.2$, paired $t$ test), or AM-251 (purple, $n=5,3$ mice, $t=12, \mathrm{df}=4, p=0.3$, paired $t$ test). Bar diagrams summarize the ratio of the SD and the mean EPSP or EPSC amplitude of the last 7 min before compared with the last 7 min after HFS delivery (as in other figures). Data are presented as mean \pm SEM.

protocol paired with postsynaptic depolarization to test synaptic plasticity changes at cortico-dSPN synapses (Fig. 1A). Consistent with previous observation (Trusel et al., 2015; Rittiner et al., 2016), HFS resulted in a persistent decrease in amplitude of EPSPs (Fig. 1B) and EPSCs (Fig. 1C). Furthermore, this persistent synaptic depression was associated with a decrease in the $\mathrm{CV}\left(\mathrm{CV}^{-2}\right)$ of EPSPs and EPSCs after HFS (Fig. 1D), which suggests a presynaptic locus of expression of plasticity (Fino et al., 2005; Trusel et al., 2015; Cavaccini et al., 2018). Taken together, these results indicate that HFS of cortico-dSPN synapses induces LTD through a presynaptic mechanism, as previously shown (Trusel et al., 2015).

We then investigated the signaling molecules involved in the HFS-LTD. First, since corticostriatal terminals release glutamate, we tested the involvement of mGluR5. In the presence of the
mGluR5 antagonist MPEP (10 $\mu \mathrm{M})$, HFS was unable to induce LTD at cortico-dSPN synapses (Fig. $1 B, C$ ), and no changes in $\mathrm{CV}^{-2}$ occurred (Fig. 1D). Therefore, mGluR5 activation is required for the induction of the HFS-LTD.

Next, since SPNs are GABAergic neurons that, once activated by excitatory inputs, release GABA, we tested whether this neurotransmitter may influence the HFS-LTD. While the contribution of $\mathrm{GABA}_{\mathrm{A}}$ Rs could be ruled out because the HFS-LTD was observed in the presence of their antagonists (see Materials and Methods), $\mathrm{GABA}_{\mathrm{B}}$ receptors might be involved. However, we found that HFS-LTD at cortico-dSPN synapses was unaffected by the $\mathrm{GABA}_{\mathrm{B}} \mathrm{R}$ antagonist CGP55845 (10 $\mu \mathrm{M}$; Fig. $1 B)$, and it was accompanied by a change in $\mathrm{CV}^{-2}$ (Fig. $1 D$ ), suggesting that $\mathrm{GABA}_{\mathrm{B}} \mathrm{R}$ activation was not involved in HFS-induced LTD. 
A

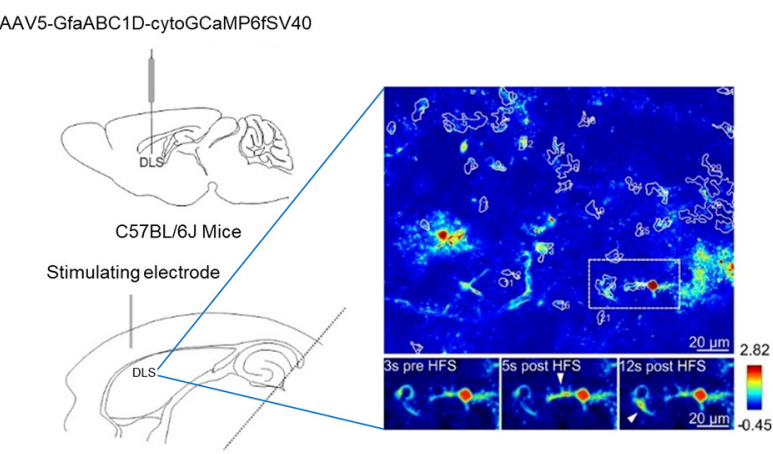

B

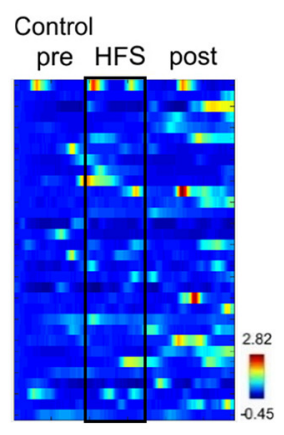

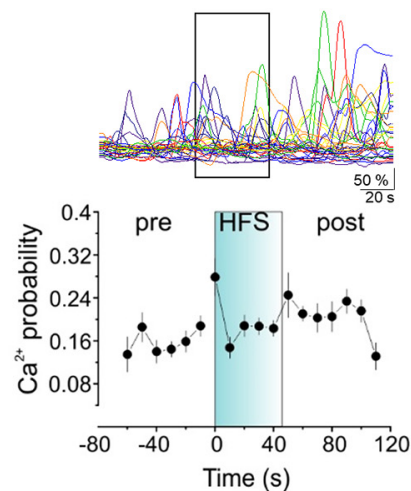

C

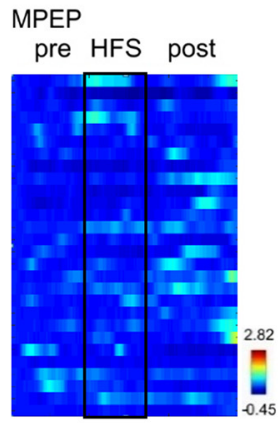

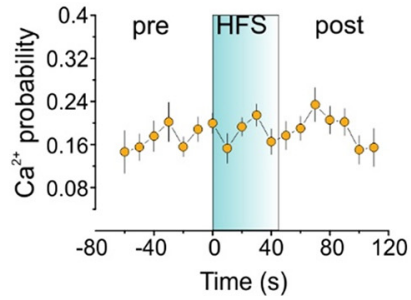

D

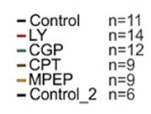

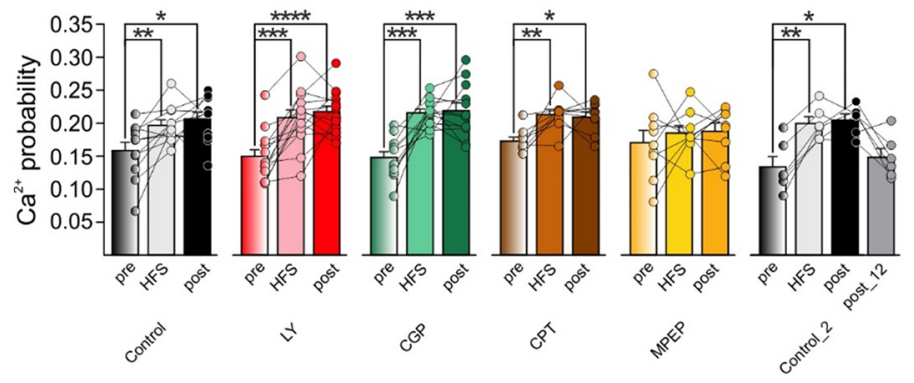

Figure 2. Cortical HFS enhances $\mathrm{Ca}^{2+}$ transients in DLS astrocytes through mGluR5 activation. $A$, top left, C57BI/6J mice received bilateral DLS injection of the genetically-encoded cytosolic $\mathrm{Ca}^{2+}$ indicator GCaMP6f under the astrocyte GfaABC1D promoter (AAV5.G, faABC1D.cytoGCaMP6f.SV40). Bottom left, Scheme of experimental configuration for two-photon Ca ${ }^{2+}$ imaging measurements in DLS astrocytes of horizontal brain slices. Right, Representative image of ROls automatically generated by CALSEE in control conditions. $\boldsymbol{B}$, Representative heatmap (left) and traces (top right) of $\mathrm{Ca}^{2+}$ fluorescence from ROls ( $y$-axis in left) before (pre), during (HFS, black box, as in other panels), and after (post) HFS delivery in control conditions. Bottom right, Time course of $\mathrm{Ca}^{2+}$ event probability averaged in 10-s bins in control conditions before, during, and after HFS delivery. C, left, Representative heatmap of Ca ${ }^{2+}$ traces from ROls ( $y$-axis) before, during, and after HFS delivery in the presence of MPEP. Right, Time course of $\mathrm{Ca}^{2+}$ event probability averaged in 10-s bins in MPEP group before, during, and after HFS delivery. D, Mean Ca ${ }^{2+}$ event probability $60 \mathrm{~s}$ before HFS (pre), during HFS (HFS), $70 \mathrm{~s}$ after HFS (post), and 12 min after HFS delivery (Post_12) in different pharmacological conditions (black, control, $n=11,5$ mice, pre vs HFS vs post, RM1WA, $F_{(10,20)}=9.082,{ }^{* *} p=0.0019$, Dunnett; red, LY, $n=14,3$ mice, RM1WA, $F_{(13,26)}=24.27,{ }^{* * * *} p<0.0001$, Dunnett; green, CGP, $n=12,2$ mice, RM1WA, $F_{(11,22)}=24.35,{ }^{* * * *} p<0.0001$, Dunnett; brown, CPT, $n=9,2$ mice, RM1WA, $F_{(8,16)}=8.736,{ }^{* *} p=0.003$, Dunnett; yellow, MPEP, $n=9,2$ mice, RM1WA, $F_{(8,16)}=0.6, p=0.5 ;$ black, Control_2, $n=6,2$ mice, RM1WA, $F_{(5,15)}=14.63,{ }^{* *} p=0.0029$, Dunnett). Data are presented as mean \pm SEM. ${ }^{*} p<0.05,{ }^{* *} p<0.01,{ }^{* * *} p<0.001$, and ${ }^{* * * *} p<0.0001$.

The HFS-LTD at cortico-dSPN synapses has been reported to be mediated by A1Rs through a presynaptic mechanism (Trusel et al., 2015). Present results agree with previous reports, showing that the HFS-LTD was absent in the presence of the A1R antagonist DPCPX (500 nм; Fig. 1C), and no associated $\mathrm{CV}^{-2}$ changes occurred (Fig. 1D).

Finally, we tested the contribution of CB1Rs. We found that HFS-LTD still occurred in the presence of the CB1R antagonist AM-251 (4 $\mu \mathrm{M}$; Fig. $1 C$ ), suggesting that CB1Rs do not contribute to this form of HFS-LTD, as previously shown (Trusel et al., 2015). Taken together, these results indicate that cortical HFS induces a presynaptic A1R-dependent and mGluR5-dependent LTD at cortico-dSPN synapses.

\section{Cortical HFS enhances $\mathrm{Ca}^{2+}$ transients in DLS astrocytes through mGluR5 activation}

Because the HFS-LTD at cortico-dSPN synapses depended on A1Rs (Fig. 1; Trusel et al., 2015; Spigolon et al., 2018) and astrocytes are known to regulate synaptic transmission and plasticity through the release of ATP/adenosine in different brain areas (Araque et al., 2014), we then investigated astrocyte involvement in mediating this form of plasticity. We first monitored astrocyte $\mathrm{Ca}^{2+}$ activity using a viral injection into the DLS of the genetically-encoded cytosolic $\mathrm{Ca}^{2+}$ indicator GCaMP6f under the astrocyte GfaABC1D promoter (AAV5-GfaABC1DcytoGCaMP6fSV40; Fig. 2A). The astrocyte $\mathrm{Ca}^{2+}$ signal activity was quantified as $\mathrm{Ca}^{2+}$ event probability (measured as the occurrence of $\mathrm{Ca}^{2+}$ events per min). In control conditions (Control), cortical HFS increased $\mathrm{Ca}^{2+}$ event probability during and immediately following the stimulation period compared with baseline (Fig. 2B,D). In a separate control experiment (Control_2), we found that the increase in $\mathrm{Ca}^{2+}$ event probability returned to baseline $12 \mathrm{~min}$ after HFS (Post_12; Fig. 2D), indicating that striatal astrocytes sensed the high-frequency activity of corticostriatal inputs.

Then, we used pharmacological tools to investigate the signaling mechanisms underlying astrocyte activation. The HFSinduced increase in $\mathrm{Ca}^{2+}$ event probability persisted in the presence of the mGluR1 antagonist LY367385 $(100 \mu \mathrm{M})$, the $\mathrm{GABA}_{\mathrm{B}} \mathrm{R}$ antagonist CGP54626 (1 mM), and the A1R antagonist CPT (2 $\mu$ m; Fig. 2D). In contrast, when mGluR5 was blocked with MPEP $(50 \mu \mathrm{M})$, HFS did not increase $\mathrm{Ca}^{2+}$ event probability (Fig. 2C,D). Therefore, in agreement with numerous previous studies demonstrating that astrocytes express mGluR5 that on activation elevate astrocytic $\mathrm{Ca}^{2+}$ in different brain areas (Porter and McCarthy, 1996; Perea and Araque, 2005; Wang et al., 
A

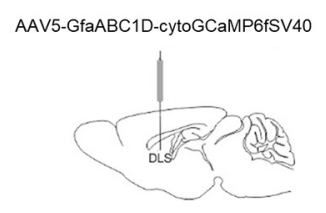

$\mathrm{IP}_{3} \mathrm{R}^{-/-1}$ Drd1_Td Tomato BAC Mice
B
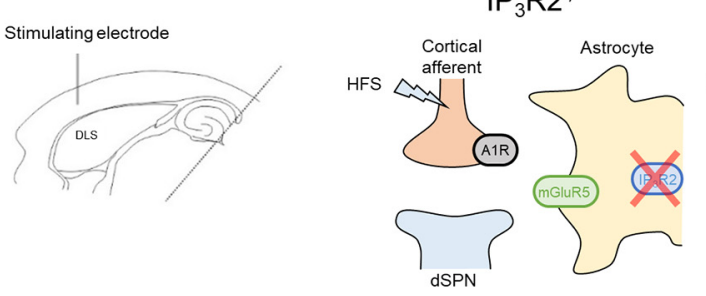

GDP $\beta S$ in astrocytes

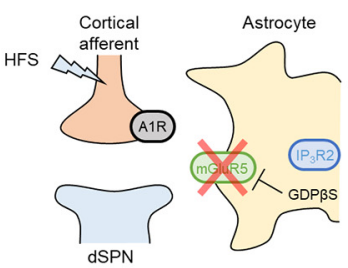

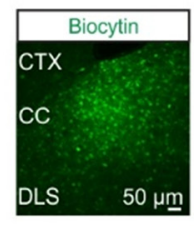

C

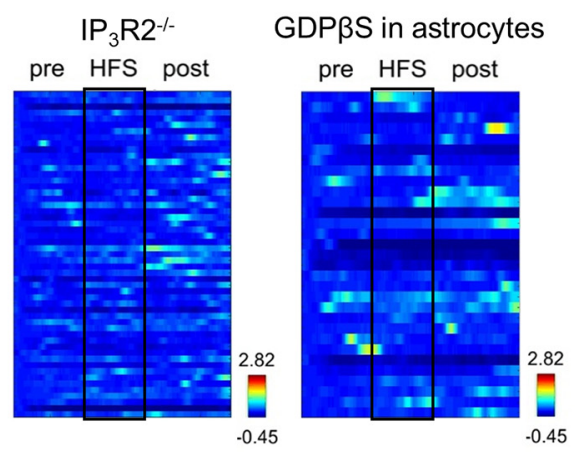

D

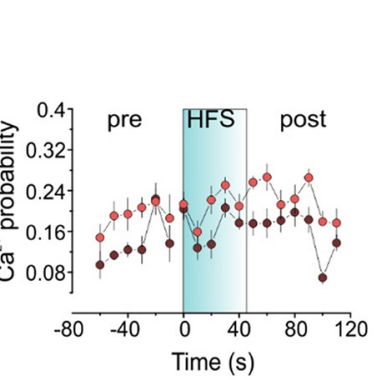

- IP3R2
$-G D P S$ in astrocytes
$n=11$
$n=10$

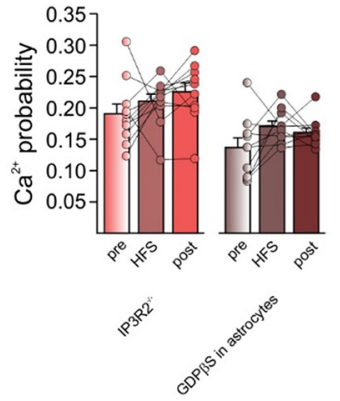

E
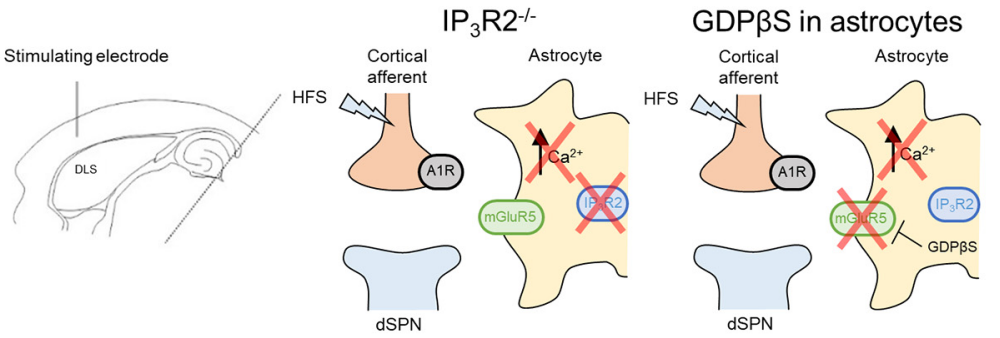

$\mathbf{F}$

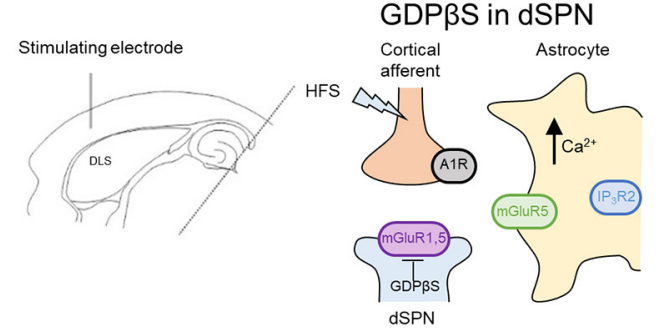

G
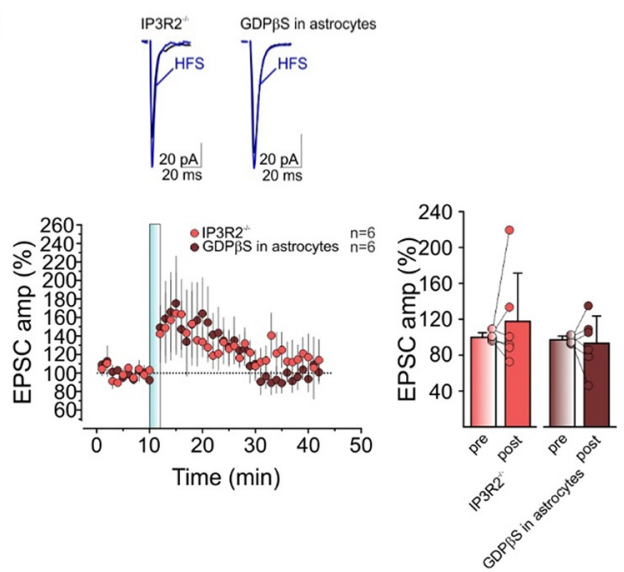

H

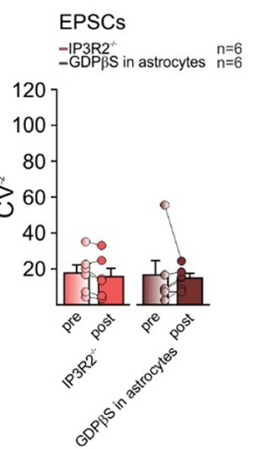

I

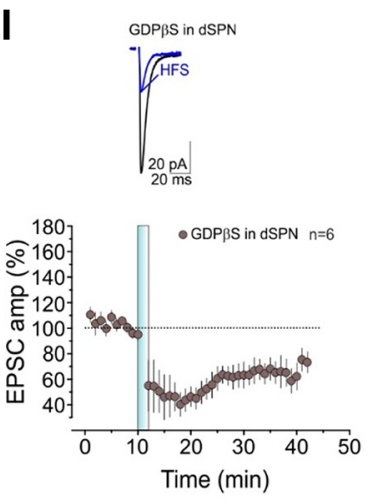

J

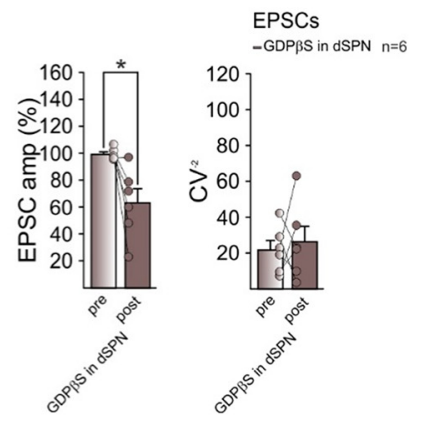

Figure 3. Blocking astrocyte $\mathrm{Ca}^{2+}$ activity prevents HFS-LTD at cortico-dSPN synapses. $A$, left, IP $\mathrm{P}_{3} \mathrm{R} 2$ knock-out mice $\left(\mathrm{IP}_{3} \mathrm{R}^{-/-}\right)$and Drd1-Td Tomato BAC mice received bilateral DLS injection of the genetically-encoded cytosolic $\mathrm{Ca}^{2+}$ indicator GCaMP6f under the astrocyte GfaABC1D promoter (AAV5-GfaABC1D-cytoGCaMP6fSV40). Right, Schematic of experimental configuration for two-photon $\mathrm{Ca}^{2+}$ imaging measurements in DLS astrocytes of horizontal brain slices. B, Scheme of the molecular mechanisms regulating HFS-LTD at tripartite synapses in IP ${ }_{3} \mathrm{R}^{-1-}$ (left) and in Drd1-Td Tomato mice with GDP $\beta$ S patch-loaded astrocytes (middle). Right, Image of immunofluorescence for biocytin of biocytin-loaded astrocyte syncytium in DLS. C, Representative heatmaps of $\mathrm{Ca}^{2+}$ traces from ROls before, during, and after HFS delivery in IP3R2 ${ }^{-1-}$ (left) and in Drd1-Td Tomato mice with GDP $\beta$ S patch-loaded astrocyte syncytium (right). D, Left, Time course of Ca ${ }^{2+}$ event probability before, during, and after HFS in $\mathrm{IP}_{3} \mathrm{R}^{-1-}$ (red, $n=11,2$ mice) and in GDP $\beta$ S patch-loaded astrocyte syncytium (brown, $n=10,2$ mice). Right, Mean Ca ${ }^{2+}$ event probability before, during, and after HFS in $\mathrm{PP}_{3} \mathrm{R}^{-1-}$ (red, $n=11,2$ mice, pre vs HFS vs post, RM1WA, $F_{(10,20)}=1.897, p=0.2$ ) and in GDP $\beta$ S patch-loaded astrocyte syncytium (brown, $n=10,2$ mice, pre vs HFS vs post, Friedman test, $p=0.1$ ). $E$, Scheme of experimental configuration (left) and the molecular mechanisms regulating HFS-LTD at tripartite synapses in $\mathrm{IP}_{3} \mathrm{R2}^{-1-}$ (middle) and in Drd1-Td Tomato mice with GDP $\beta$ S patch-loaded astrocytes (right). F, Scheme of experimental configuration (left) and the molecular mechanisms regulating HFS-LTD at tripartite synapses in C57BI/6J mice with GDP $\beta$ S patch-loaded dSPN (right). G, top, Averaged recordings (10 EPSCS) before (black) and after (blue) HFS. Bottom left, Relative EPSC amplitudes before and after HFS in IP $R_{3} 2^{-1-}$ (red, $n=6,5$ mice) and in Drd1-Td Tomato mice with GDP $\beta$ S patch-loaded astrocyte syncytium (brown, $n=6,4$ mice). Bottom right, Mean normalized EPSC amplitudes before and after HFS in IP R2 ${ }^{-1-}$ (red, $n=6,5$ mice, $t=0.8, \mathrm{df}=5, p=0.5$, paired $t$ test) and $\mathrm{GDP} \beta \mathrm{S}$ in astrocytes (brown, $n=6,4$ mice, $t=0.3, \mathrm{df}=5, p=0.8$, paired $t$ test). $\boldsymbol{H}$, Mean $\mathrm{CV}^{-2}$ before and after HFS in IP $\mathrm{R}_{3}^{-1-}$ (red, $n=6,5$ mice, $t=1.7, \mathrm{df}=5, p=0.16$, paired $t$ test) and in GDP $\beta$ S in astrocytes (brown, $n=6,4$ mice, $W=7, p=0.56$, Wilcoxon matched-pairs signed-rank test). $I$, top, Averaged recordings (10 EPSCs) before (black) and after (blue) HFS. Bottom left, Relative EPSC amplitudes before and after HFS in C57BI/6J mice with GDP $\beta$ S patch-loaded dSPN (gray, $n=6,4$ mice). Bottom right, Mean normalized EPSC amplitudes before and after HFS in GDP $\beta$ S patch-loaded dSPN (gray, $n=6,4$ mice, $t=3.3, \mathrm{df}=5,{ }^{*} p=0.02$, paired $t$ test). $J$, Mean $\mathrm{CV}^{-2}$ before and after HFS in GDP $\beta S$ patch-loaded dSPN (gray, $n=6,4$ mice, $t=0.4, \mathrm{df}=5, p=0.7$, paired $t$ test). Data are presented as mean \pm SEM. 
A

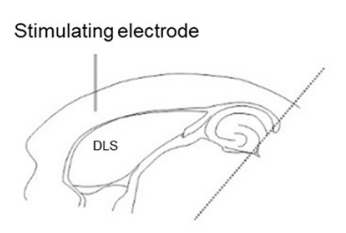

C

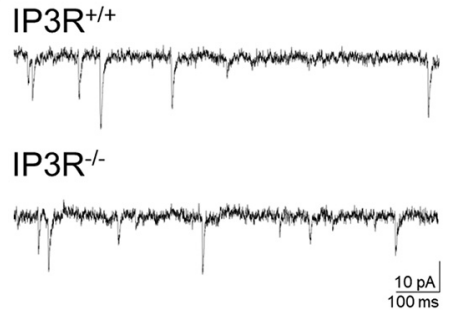

B
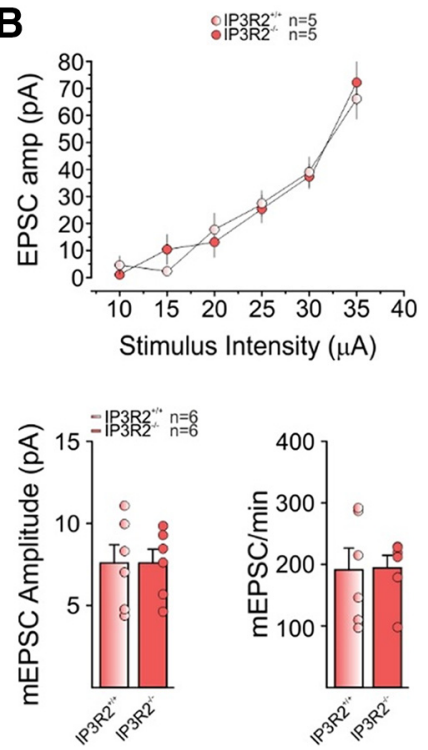

Figure 4. Basal synaptic transmission is not affected in IP3R2 ${ }^{-1-}$ mice. $A$, Experimental configuration in horizontal brain slices of IP3R2 ${ }^{-1-}$ and wild-type (WT) littermates. $\boldsymbol{B}$, Changes in EPSC amplitude evoked by different stimulus intensities in IP3R2 $^{-1-}$ (light red, $n=5,2$ mice) and WT littermates (red, $n=5,2$ mice; $F_{(1,5)}=86.10$, RM1WA, $\left.p=0.07\right)$ ). C, left, Representative traces of miniature EPSCS (mEPSCs) in IP3R2 ${ }^{-1-}$ (bottom) and WT littermates (top). Right, Mean mEPSC amplitude (pA) in IP3R2 ${ }^{-1-}$ (red, $n=6,2$ mice) and WT littermates (light red, $n=6,2$ mice, $t=0.00,019, \mathrm{df}=10, p=0.99, t$ test) and mean $\mathrm{mEPSC} / \mathrm{min}$ in IP3R2 ${ }^{-1-}$ (red, $n=6,2$ mice) and WT littermates (light red, $n=6,2$ mice, $t=0.07, \mathrm{df}=10$, $p=0.94, t$ test $)$.

2006a; Di Castro et al., 2011; Panatier et al., 2011), these results suggest that the DLS astrocytic responses to cortical HFS are mediated by mGluR5.

\section{Blocking astrocyte $\mathrm{Ca}^{2+}$ activity prevents HFS-LTD at dSPN synapses}

Given that both HFS-LTD and astrocyte responses to HFS depended on mGluR5 (Figs. 1, 2, respectively), we hypothesized that astrocytes are an integral component mediating the HFSLTD. Thus, we next asked whether blocking astrocyte activity would influence HFS-LTD. Since mGluR5 are GPCRs, whose activation mobilizes $\mathrm{Ca}^{2+}$ through an $\mathrm{IP}_{3}$-mediated mechanism (Nakahara et al., 1997; D’Ascenzo et al., 2007), we applied two complementary strategies. First, we used $\mathrm{IP}_{3} \mathrm{R} 2$ knock-out mice (Li et al., 2005), in which $\mathrm{IP}_{3} \mathrm{R} 2$-mediated $\mathrm{Ca}^{2+}$ signaling in astrocytes is largely absent (Fig. 3B; Durkee et al., 2019). Second, we specifically blocked astrocyte GPCR signaling by loading the astrocytic syncytium with the G-protein inhibitor GDP $\beta$ S (10 $\mu \mathrm{M}$; Fig. $3 B$ ). As suggested by the spreading of the fluorescent signal across cells on patch-loading an astrocyte with biocytin (Fig. 3B), astrocytes in the DLS are gap-junction coupled to form an astrocyte syncytium. Both the HFS-evoked $\mathrm{Ca}^{2+}$ signaling (Fig. $3 A-D$ ) and the HFS-LTD (Fig. $3 E-H$ ) were prevented in $\mathrm{IP}_{3} \mathrm{R} 2^{-1-}$ mice and in mice with $\mathrm{GDP} \beta$ S-loaded astrocyte syncytium.

To test the possibility of indirect effects of chronic global $\mathrm{IP}_{3} \mathrm{R} 2$ deletion on the potential to induce LTD in $\mathrm{IP}_{3} \mathrm{R} 2^{-/-}$mice, we assessed basal synaptic transmission properties in $\mathrm{IP}_{3} \mathrm{R} 2^{-1-}$ and wild-type $\left(\mathrm{IP}_{3} \mathrm{R} 2^{+/+}\right)$littermates (Fig. 4). We found that the input-output relationship of corticostriatal stimulation and evoked EPSC amplitude revealed no significant differences between wild-type and $\mathrm{IP}_{3} \mathrm{R} 2^{-1-}$ mice at the stimulation intensities tested (Fig. 4B). Furthermore, both the amplitude and frequency of miniature EPSCs were unaffected in $\mathrm{IP}_{3} \mathrm{R} 2^{-/-}$mice (Fig. $4 C$ ). The unaltered basal synaptic transmission in $\mathrm{IP}_{3} \mathrm{R} 2^{-1-}$ mice suggests that the observed absence of HFS-LTD was not due to changes in synaptic transmission properties, but to the astrocyte signaling impairment. Altogether, these results indicate that $\mathrm{IP}_{3} \mathrm{R} 2$-mediated and GPCR-mediated astrocyte $\mathrm{Ca}^{2+}$ signaling was required for eliciting the HFS-LTD.

To further test this idea, we blocked the postsynaptic neuronal GPCR signaling by patch-loading dSPN with GDP $\beta S(10 \mu \mathrm{M})$ and found that this manipulation had no effect on HFSLTD (Fig. 3I,J), thus corroborating that astrocytic, not postsynaptic neuronal, GPCR signaling is necessary for HFSLTD at cortico-dSPN synapses. Taken together, our data suggest that HFS evokes the release of cortical glutamate that activates DLS astrocytes, through mGluR5 activation (see above), resulting in a GPCR-mediated and $\mathrm{IP}_{3} \mathrm{R} 2$-mediated $\mathrm{Ca}^{2+}$ increase that is necessary to induce HFS-LTD at cortico-dSPN synapses.

\section{Astrocyte $G_{q}$ DREADD activation induces A1R-dependent LTD at dSPN synapses}

To investigate whether directly activating astrocytes is sufficient for inducing the depression of EPSC amplitude at cortico-dSPN synapses, we used a $\mathrm{G}_{\mathrm{q}}$ DREADDs chemogenetic approach (Fig. 5). This approach has previously been shown to reliably elevate astrocyte $\mathrm{Ca}^{2+}$ in a phospholipase C (PLC)-dependent and $\mathrm{IP}_{3} \mathrm{R} 2$-dependent manner on application of the DREADD ligand CNO (Chai et al., 2017; Martin-Fernandez et al., 2017; Durkee et al., 2019). We injected in the DLS the virus AAV8-GFAPhM3Dq-mCherry that contains the $\mathrm{G}_{\mathrm{q}}$ DREADD hM3Dq, the astroglial promoter GFAP and the reporter mCherry (Fig. 5A). First, we confirmed through immunohistochemistry (Fig. 5B; $n=3$ mice) that expression of the virus was largely specific to astrocytes (GFAP+ cells; penetrance: 99.6\%, 1010 cells), with negligible penetrance in neurons $(3.3 \%$ of NeuN+ cells, 1661 cells), microglia ( $1.2 \%$ of Iba + cells, 81 cells; data not shown), NG2 glia ( $0 \%$ of NG2 + cells, 28 cells; data not shown), and oligodendrocytes $(1.8 \%$ of Oligo $2+$ cells, 281 cells; data not shown).

In a region of DREADD-expressing astrocytes, we observed that $\mathrm{CNO}$ application $(10 \mu \mathrm{M})$ increased astrocyte $\mathrm{Ca}^{2+}$ event probability (Fig. 5C). This effect was absent in control mice injected with the virus AAV8-GFAP-mCherry (i.e., lacking the $\mathrm{G}_{\mathrm{q}}$ DREADD; Fig. 5C). Next, we asked whether this CNOinduced increase in astrocyte $\mathrm{Ca}^{2+}$ levels would suppress EPSCs in an adenosine A1R-dependent manner similar to that observed for HFS-evoked LTD. We found that in mice with DREADDexpressing astrocytes, $\mathrm{CNO}$ perfusion for $30 \mathrm{~min}$ induced depression of EPSC amplitude (Fig. 5D,E), whereas this effect was absent in control mice injected with AAV8-GFAP-mCherry (Fig. 5E). Furthermore, in the presence of the A1R antagonist 
A

AAV8-GFAP-mCherry/AAV8-GFAP-hM3Dq_mCherry AAV5-GfaABC1D-cytoGCaMP6fSV 40

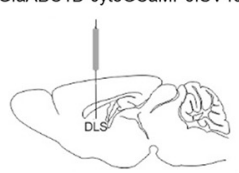

C57BL/6J Mice

B

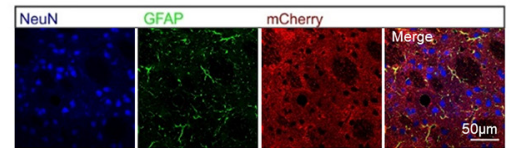

D

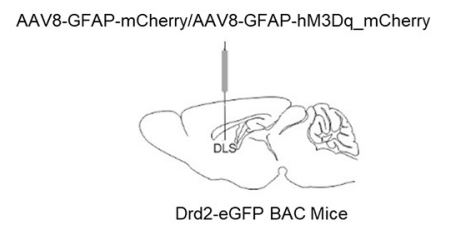

$\mathbf{E}$

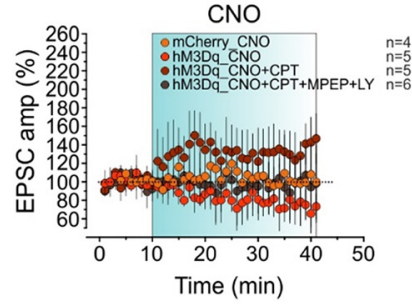

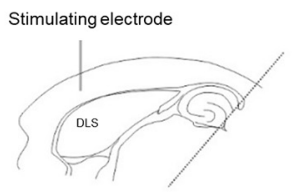

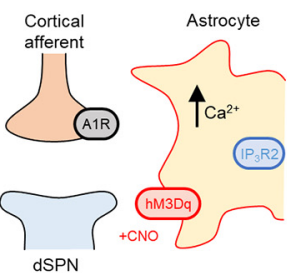

C
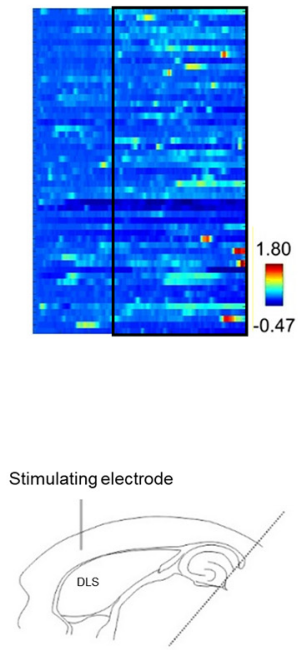
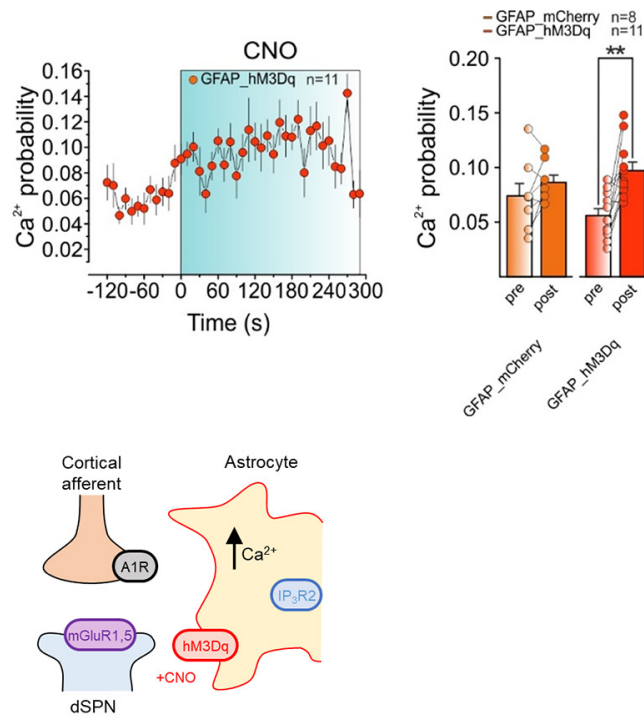

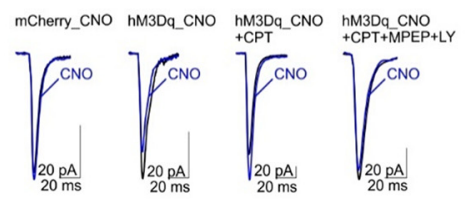

Figure 5. Astrocyte Gq DREADD activation induces A1R-dependent LTD at cortico-dSPN synapses. $A$, left, C57BL/6J mice received bilateral DLS injection of AAV5-GfaABC1D-cytoGCaMP6fSV40 along with either AAV8-GFAP-mCherry (control condition) or AAV8-GFAP-hM3Dq-mCherry virus. Middle, Schematic of experimental configuration for two photon Ca ${ }^{2+}$ imaging measurements in DLS astrocytes of horizontal brain slices. Right, Scheme of the molecular mechanisms regulating synaptic plasticity at tripartite synapses in C57BI/6J mice with astrocyte-specific Gq DREADDs. B, Confocal laser scanning microscope image of immunohistochemistry showing colocalization of hM3Dq-mCherry with the astrocytic marker GFAP, but not with the neuronal marker NeuN. C, left, Representative heatmap of $\mathrm{Ca}^{2+}$ traces from ROls before and during CNO bath application in mice expressing AAV8-GFAP-hM3Dq-mCherry. Middle, Time course of Ca ${ }^{2+}$ event probability before and after (last $4 \mathrm{~min}$ ) CNO bath application in mice expressing AAV8-GFAP-hM3Dq-mCherry. Right, mean $\mathrm{Ca}^{2+}$ event probability before (pre) and after (post) CNO bath application in mice expressing AAV8-GFAP-mCherry (control condition; orange, $n=8,2$ mice, $t=1.5, \mathrm{df}=7, p=0.2$, paired $t$ test) or AAV8-GFAP-hM3Dq-mCherry (red, $n=11,2$ mice, $t=4, \mathrm{df}=10$, ${ }^{* *} p=0.002$, paired $t$ test). D, left, Drd2_eGFP mice received bilateral DLS injection of AAV8-GFAP-mCherry (control condition) or AAV8-GFAP-hM3Dq-mCherry virus. Middle, Scheme of experimental condition. Right, Scheme of the molecular mechanisms regulating synaptic plasticity at tripartite synapses in C57BI/6J mice with astrocyte-specific Gq DREADDs. $E$, left, Averaged recordings (10 EPSCs) before (black) and after (blue) CNO bath application. Middle, Relative EPSC amplitudes before and after CNO bath application in mice expressing AAV8-GFAP-mCherry (orange, $n=4,3$ mice), or in mice expressing AAV8-GFAP-hM3Dq-mCherry in control (red, $n=5,5$ mice), in (PT (maroon, $n=5,4$ mice), or in (PT plus MPEP and LY (gray, $n=6,4$ mice). Right, Mean normalized EPSC amplitudes before and after CNO in mice expressing AAV8-GFAP-mCherry (orange, $n=4,3$ mice, $W=0, p>0.9999$, Wilcoxon matched-pairs signed-rank test), or in mice expressing AAV8-GFAP-hM3Dq-mCherry in control (red, $n=5,5$ mice, $t=3.6, \mathrm{df}=4,{ }^{*} p=0.02$, paired $t$ test), in CPT (maroon, $n=5,4$ mice, $t=4.3, \mathrm{df}=4,{ }^{*} p=0.01$, paired $t$ test) or in CPT plus MPEP and LY (gray, $n=6,4$ mice, $t=0.2, \mathrm{df}=5, p=0.9$, paired $t$ test). $\boldsymbol{F}$, Mean CV ${ }^{-2}$ before and after CN0 in mice expressing AAV8-GFAP-mCherry (orange, $n=4,3$ mice, $W=0, p>0.9999$, Wilcoxon matched-pairs signed-rank test), in mice expressing AAV8-GFAP-hM3Dq-mCherry in control (red, $n=5,5$ mice, $W=-7, p=0.44$, Wilcoxon matched-pairs signed-rank test), in (PT (maroon, $n=5,4$ mice, $W=13, p=0.13$, Wilcoxon matched-pairs signed-rank test), or in CPT plus MPEP and LY (gray, $n=6,4$ mice, $t=1.3, \mathrm{df}=5, p=0.26$, paired $t$ test). Data are presented as mean \pm SEM. 
A

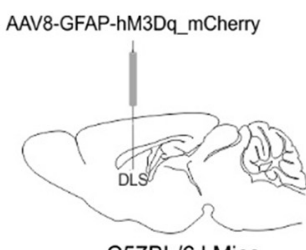

C57BL/6J Mice
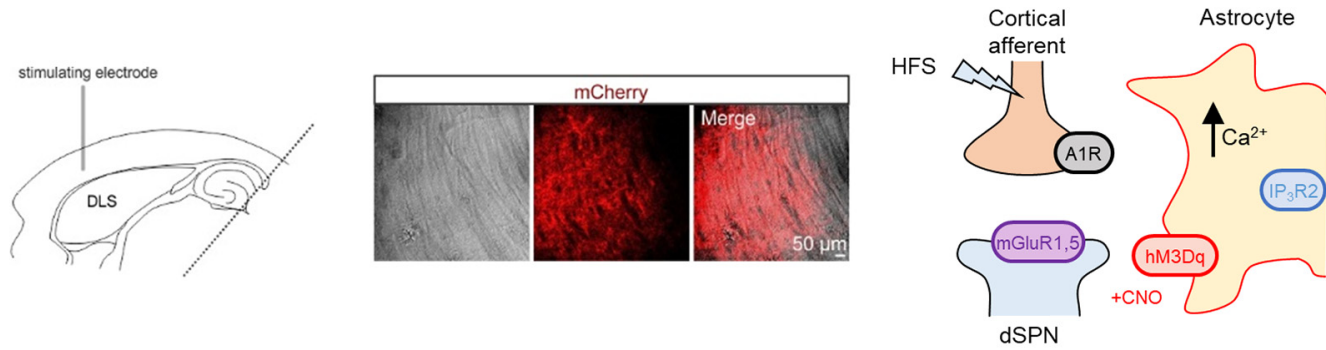

B

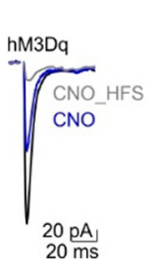

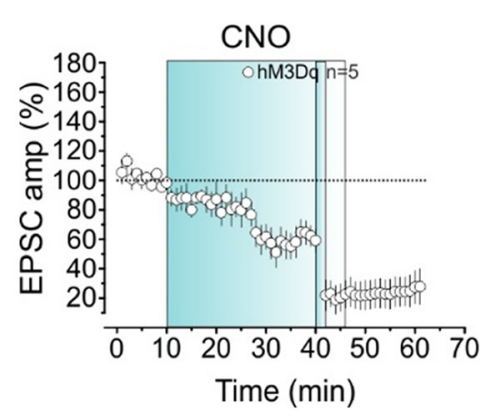

C

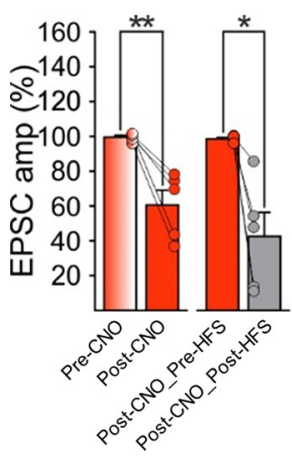

D

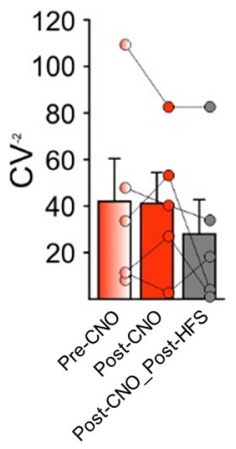

Figure 6. CNO-induced synaptic depression does not occlude HFS-LTD. $A$, left, C57BL/6J mice received bilateral DLS injection of AAV8-GFAP-hM3Dq-mCherry. Middle left, Experimental configuration in horizontal brain slices. Middle right, Bright field image (left) and confocal laser scanning microscope image (middle) showing the expression of mCherry in the DLS. Right, Scheme of the molecular mechanisms regulating synaptic plasticity at tripartite synapses in C57BI/6J mice with astrocyte-specific Gq DREADDs. B, Left, Averaged recordings (10 EPSCs) before CNO bath application (black), after CNO bath application (blue), and after CNO+HFS (gray). Right, Relative EPSC amplitudes (relative to Pre-CNO) before and after CNO bath application and subsequent HFS in C57BL/6J mice expressing AAV8-GFAP-hM3Dq-mCherry. C, Relative mean EPSC amplitudes 5 min before (Pre-CNO) and 25-30 min after CNO (Post-CNO; red, $n=5,3$ mice; Pre-CNO vs Post-CNO, $t=4.8, \mathrm{df}=4,{ }^{* *} p=0.009$, paired $t$ test) and relative mean EPSCS amplitudes 5 min before (Post-CNO_Pre-HFS) and 15-20 min after HFS (Post-CNO_Post-HFS; silver, $n=5,3$ mice; Post-CNO_Pre-HFS vs Post-CNO_Post-HFS, $t=4.1, \mathrm{df}=4,{ }^{*} p=0.015$, paired $t$ test). $\boldsymbol{D}$, Mean $\mathrm{CV}^{-2}$ before (orange) and after (red) CNO application and subsequent HFS (silver; $n=5,3$ mice, RM1WA $F_{(4,8)}=0.87, p=0.45$. All data are presented as mean \pm SEM.

CPT $(2 \mu \mathrm{M})$, not only was the CNO-induced LTD prevented in mice with DREADD-expressing astrocytes but the EPSC amplitude was surprisingly potentiated (Fig. $5 E$ ). This CNO-induced potentiation occurred with no significant changes in $\mathrm{CV}^{-2}$ and was abolished by antagonizing A1Rs with CPT and Group I mGluRs with MPEP (mGluR5) and LY367385 (mGluR1; Fig. $5 E, F)$.

We then tested whether the $\mathrm{CNO}$-evoked synaptic depression occluded the HFS-LTD (Fig. 6). We first applied CNO, which persistently depressed the EPSC amplitude (Fig. 6B,C; compare with Fig. 5E). Indeed, EPSC amplitudes recorded 25-30 min after $\mathrm{CNO}$ application (Post-CNO) were significantly reduced relative to $5 \mathrm{~min}$ of baseline (Pre-CNO; Fig. 6B,C). Then, $30 \mathrm{~min}$ after applying CNO, we delivered the HFS protocol, which still induced LTD manifested as a further depression of the EPSC amplitude (Fig. 6B,C). Indeed, the amplitude of EPSCs recorded 15-20 min after HFS (Post-CNO_Post-HFS) was significantly depressed from amplitudes recorded $5 \mathrm{~min}$ before the HFS (i.e., after CNO; Post-CNO_Pre-HFS; Fig. 6B,C). Since HFS still depressed EPSC amplitude after the initial CNO-evoked EPSC depression, these results indicate that HFS-LTD was not occluded by the previous depression induced by CNO, suggesting that the mechanisms underlying CNO-induced LTD were not saturated or that additional mechanisms triggered by $\mathrm{CNO}$ may be present (see Discussion).

\section{Discussion}

The present results propose that astrocytes are integral to HFSinduced LTD at cortico-dSPN synapses in the DLS. We found that striatal astrocytes respond to HFS with $\mathrm{Ca}^{2+}$ elevations dependent on mGluR5, G-protein signaling, and $\mathrm{IP}_{3} \mathrm{R} 2$ activation. Blocking signaling from any of those sources prevented HFS-LTD, suggesting that astrocytic mGluR5-mediated GPCR signaling and internal release of $\mathrm{Ca}^{2+}$ via $\mathrm{IP}_{3} \mathrm{R} 2$ are required for the induction of LTD. Furthermore, activating striatal astrocytes with $G_{\mathrm{q}}$ DREADDs in the absence of cortical HFS mimicked the LTD in an A1R-dependent manner. Since astrocytes are able to release ATP/adenosine in different brain areas (Volterra and Meldolesi, 2005; Araque et al., 2014), present results suggest that astrocytes may be the origin of ATP/adenosine that mediates this form of striatal LTD (Trusel et al., 2015; Spigolon et al., 2018). These findings better elucidate the full complement of astrocyte function on synaptic plasticity in the DLS.

\section{Adenosine and glutamate gate HFS-LTD at direct corticostriatal synapses}

We report here that HFS-induced LTD at cortico-dSPN synapses is mediated by A1Rs, which is consistent with recent observation (Trusel et al., 2015). A1R is expressed in many brain regions at glutamatergic terminals and, given that it is $G_{i / o}$ coupled, its activation results in a decrease in glutamate release (Fredholm et al., 2005). Interestingly, while several studies implicated adenosine/ A1R signaling in striatal plasticity (Lovinger and Choi, 1995; Ciruela et al., 2006; Borycz et al., 2007), the adenosine origin remained undefined. In the hippocampus, adenosine signaling was originally shown to mediate heterosynaptic depression via presynaptic A1R-mediated suppression of glutamate release (Manzoni et al., 1994), but the mechanisms upstream of A1R activation were unknown. Later studies demonstrated that hippocampal heterosynaptic depression is mediated by astrocyticderived adenosine (Zhang et al., 2003; Pascual et al., 2005; 
Serrano et al., 2006). Present results suggest that astrocytic release of ATP/adenosine might be a general mechanism involved in synaptic depression. Further studies in other brain areas are required to test this exciting and likely possibility.

In addition to requiring A1R, HFS-LTD was also dependent on mGluR5 activation. This finding is consistent with previous reports showing that activation of Group I mGluRs can mediate both LTD and LTP in the striatum (Sung et al., 2001; Gubellini et al., 2003; Lüscher and Huber, 2010). The mechanisms underlying striatal LTD are largely disputed, particularly regarding LTD at cortico-dSPN versus cortico-iSPN synapses, but in general, it is thought that postsynaptic Group I mGluR and L-type $\mathrm{Ca}^{2+}$ channel activation results in the mobilization of eCBs that bind presynaptic CB1Rs to suppress glutamate release (Gerdeman et al., 2002; Kreitzer and Malenka, 2007; Atwood and Lovinger, 2017). Studies have shown that pharmacological activation of Group I mGluRs is sufficient to induce eCB-mediated LTD and that blocking Group I mGluRs prevents LTD induction (Calabresi et al., 1999; Sung et al., 2001; Kreitzer and Malenka, 2007; Shen et al., 2008; Yin et al., 2008; Chepkova et al., 2009; Fino and Venance, 2010; Trusel et al., 2015). In the present study, the mGluR5 antagonist MPEP indeed blocked both the HFS-induced LTD and the striatal astrocyte responses. Interestingly, Trusel and colleagues found that HFS-LTD at corticodSPN synapses was not dependent on postsynaptic $\mathrm{Ca}^{2+}$ or on eCB signaling, the latter of which was also found in the present study (Trusel et al., 2015). Furthermore, we also found that blocking dSPN GPCR signaling did not affect HFS-LTD. Together, these data argue against the requirement for postsynaptic neuronal Group I mGluR-mediated $\mathrm{Ca}^{2+}$ and eCB signaling to induce LTD at cortico-dSPN synapses.

\section{Corticostriatal HFS activates astrocytes via mGluR5}

In addition to being expressed neuronally, mGluR5 is also expressed on striatal astrocytes and results in gliotransmitter release (Biber et al., 1999; D'Ascenzo et al., 2007; Bradley and Challiss, 2012; Tamura et al., 2014). Despite controversy regarding mGluR5-dependent $\mathrm{Ca}^{2+}$ signaling in adult mice (Sun et al., 2013), a number of subsequent studies have observed such signaling (Tamura et al., 2014; Chai et al., 2017; Durkee et al., 2019). Indeed, we found that blocking mGluR5 prevented both the HFS-induced astrocyte response and LTD. Although we did not specifically interrogate mGluR5 signaling in astrocytes and contribution of neuronal mGluR 5 cannot be ruled out, the fact that astrocytic mGluR5 activation elevates astrocytic $\mathrm{Ca}^{2+}$ in different brain areas (Porter and McCarthy, 1996; Perea and Araque, 2005; Wang et al., 2006a; Di Castro et al., 2011; Panatier et al., 2011; Covelo and Araque, 2018) suggests that present results are indicative of astrocytic mGluR5 involvement in HFSLTD. Antagonizing mGluR1 did not influence the astrocytic response but has previously been found to prevent HFS-LTD (Gubellini et al., 2003), suggesting that neuronal mGluR1 and astrocytic mGluR5 may work in concert to induce HFS-LTD. Of note, $\mathrm{GABA}_{\mathrm{B}}$ receptors, which have been found to mediate hippocampal heterosynaptic depression (Zhang et al., 2003; Pascual et al., 2005; Serrano et al., 2006; Covelo and Araque, 2018), are not involved in the astrocyte response to HFS and HFS-LTD. Importantly, while A1R antagonism blocked HFS-LTD, we found that it did not block the astrocytic $\mathrm{Ca}^{2+}$ response, indicating that $\mathrm{A} 1 \mathrm{R}$ activation is downstream of astrocyte activation. Taken together, these data suggest that A1R-mediated HFS-LTD occurs following mGluR5-mediated astrocyte activation.

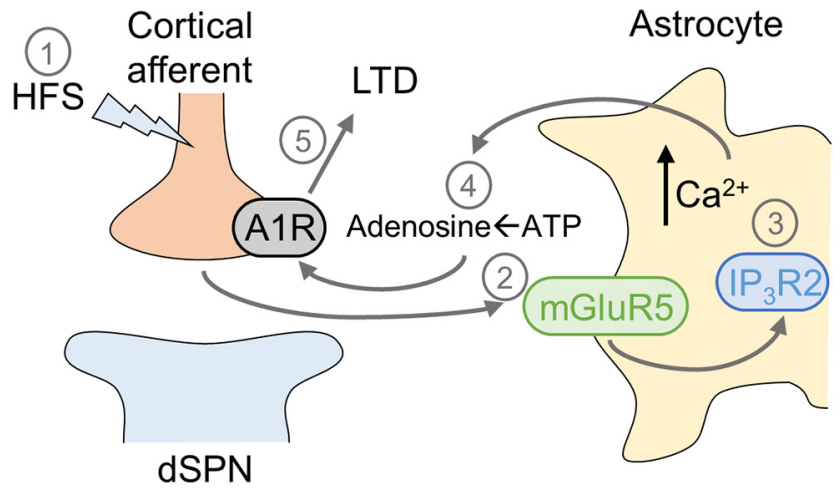

Figure 7. Working model of astrocyte-mediated LTD at cortico-dSPN synapses. HFS of deep Layer $V$ of somatosensory cortex (1) induces glutamate release from cortical afferents that activates mGluR5 on astrocytes (2), leading to GPCR-IP ${ }_{3} R 2$-mediated $\mathrm{Ca}^{2+}$ increases (3), and extracellular accumulation of astrocyte-derived adenosine (4). Adenosine activates A1R located on cortical afferents to suppress subsequent glutamate release, resulting in LTD (5).

\section{Blocking astrocyte GPCR and $\mathrm{IP}_{3} \mathrm{R} 2$ signaling prevents HFS- LTD}

To more directly investigate astrocyte involvement in HFS-LTD, we prevented $\mathrm{IP}_{3} \mathrm{R} 2$-mediated $\mathrm{Ca}^{2+}$ signaling in astrocytes with $\mathrm{IP}_{3} \mathrm{R}^{-1-}$ mice or blocked GPCR signaling via patch-loading GDP $\beta$ S into the astrocyte syncytium. In these conditions, HFS did not increase astrocyte $\mathrm{Ca}^{2+}$ signaling nor did it produce LTD. These data suggest that blocking the astrocyte $\mathrm{Ca}^{2+}$ response to cortical HFS prevents a form of astrocyte-neuron signaling that is necessary for the observed A1R-mediated suppression of glutamate release. Taken together, these data show that disrupting $\mathrm{Ca}^{2+}$ signaling in astrocytes prevents HFS-LTD at cortico-dSPN synapses, suggesting that LTD is mediated by presynaptic A1R and that the source of adenosine appears to be astrocytic.

\section{Activating astrocytes with $\mathrm{G}_{\mathrm{q}}$ DREADDs depresses synaptic strength at cortico-dSPN synapses}

We found that $G_{q}$ DREADD activation in astrocytes persistently depressed EPSC amplitude through A1R activation (Fig. 5E). Furthermore, in the presence of the A1R antagonist CPT, CNO application in $G_{\mathrm{q}}$ DREADD-expressing astrocytes induced a long-lasting synaptic potentiation that was sensitive to Group I mGluR antagonists (Fig. 5E). Interestingly, it has been reported in the DLS that astrocyte $\mathrm{Ca}^{2+}$ elevations induced by eCBs or $\mathrm{Ca}^{2+}$ uncaging stimulate the release of glutamate that increases synaptic transmission at distant synapses through activation of Group I mGluRs (Martín et al., 2015). Thus, astrocytes may potentially release both ATP/adenosine and glutamate with $\mathrm{G}_{\mathrm{q}}$ DREADD activation, each of which would oppose the effect of the other on corticostriatal glutamate release. Indeed, it was recently demonstrated in the hippocampus that low levels of stimulation activated single astrocytes to release glutamate and that higher levels of stimulation resulted in corelease of both glutamate and ATP/adenosine, resulting in a biphasic effect on synaptic transmission: an initial Group I mGluR-mediated potentiation and a secondary A1R-mediated depression (Covelo and Araque, 2018). Accordingly, $G_{\mathrm{q}}$ DREADD activation in the present study may have led to release of both glutamate and ATP/adenosine, whereby the adenosine-mediated depression was attenuated by glutamate-mediated potentiation. In line with this, the A1R antagonist CPT blocked the CNO-induced depression and instead revealed an enhancement of synaptic 
transmission that was dependent on Group I mGluRs. It is interesting that HFS-evoked astrocyte activation did not appear to induce an initial glutamate-mediated potentiation followed by adenosine-mediated depression. Nor did HFS in the presence of the A1R antagonist result in LTP. Furthermore, present results show that HFS-LTD was not occluded by the previous synaptic depression induced by CNO (Fig. 6B,C), suggesting that the mechanisms underlying LTD were not saturated. Alternatively, $\mathrm{CNO}$ activation of $\mathrm{G}_{\mathrm{q}}$ DREADD-expressing astrocytes may trigger additional mechanisms involving alternative signaling pathways. Further studies, out of the scope of the present work, are required to determine the potential contribution of astrocytic glutamate, which is released from astrocytes activated by eCBs or $\mathrm{Ca}^{2+}$ uncaging (Martín et al., 2015). As shown in other brain areas, different modalities of astrocyte activation have differential effects on gliotransmission and on its synaptic regulatory effects (Covelo and Araque, 2018; Savtchouk and Volterra, 2018; Durkee and Araque, 2019).

Taken together, these data suggest that chemogenetically-activated DLS astrocytes have the potential to regulate extrasynaptic levels of both glutamate and ATP/adenosine, with sustained chemogenetic activation resulting in the predominance of adenosine-mediated inhibition over glutamate-mediated potentiation. HFS-induced astrocyte activation, however, led only to the A1Rmediated synaptic depression. Whether this is due to a predominance of adenosine-mediated over glutamate-mediated effects or whether glutamate-mediated regulation occurs at relatively distant heterosynapses (Martín et al., 2015), and which were not monitored in the present study, will be a matter of future investigations. Nevertheless, the present results add to the complexity of bidirectional astrocyte-neuron signaling, showing the capability of astrocytes to respond to different stimuli that may trigger different downstream signaling effects on gliotransmitter release and synaptic regulation (Perea and Araque, 2005; Shigetomi et al., 2008).

In summary, present data show that astrocyte $\mathrm{Ca}^{2+}$ signaling is necessary for A1R-mediated LTD at cortico-dSPN synapses in the DLS. First, striatal astrocytes respond to cortical HFS with $\mathrm{Ca}^{2+}$ increases mediated by mGluR5, GPCR, and $\mathrm{IP}_{3} \mathrm{R} 2$ signaling. Second, blocking astrocyte signaling prevented LTD induction. Lastly, activating astrocytes induced LTD at cortico-dSPN synapses in a A1R-dependent manner. Thus, since astrocytes have been shown to respond in different brain areas to glutamatergic signaling and to release ATP/adenosine (Araque et al., 2014; Gundersen et al., 2015; Illes et al., 2019), we propose that astrocyte mGluR5-mediated $\mathrm{Ca}^{2+}$ signaling and downstream release of ATP/adenosine levels are integral to LTD at corticodSPN synapses (Fig. 7). These results reveal a key role of astrocytes in striatal synaptic plasticity.

\section{References}

Adermark L, Lovinger DM (2007) Retrograde endocannabinoid signaling at striatal synapses requires a regulated postsynaptic release step. Proc Natl Acad Sci USA 104:20564-20569.

Araque A, Carmignoto G, Haydon PG, Oliet SH, Robitaille R, Volterra A (2014) Gliotransmitters travel in time and space. Neuron 81:728-739.

Atwood BK, Lovinger DM (2017) Endocannabinoid-dependent synaptic plasticity in the striatum. In: Endocannabinoids and lipid mediators in brain functions (Melis M, ed), pp 109-153. Cham: Springer International Publishing.

Augustin SM, Chancey JH, Lovinger DM (2018) Dual dopaminergic regulation of corticostriatal plasticity by cholinergic interneurons and indirect pathway medium spiny neurons. Cell Rep 24:2883-2893.

Bagetta V, Picconi B, Marinucci S, Sgobio C, Pendolino V, Ghiglieri V, Fusco FR, Giampà C, Calabresi P (2011) Dopamine-dependent long-term depression is expressed in striatal spiny neurons of both direct and indirect pathways: implications for Parkinson's disease. J Neurosci 31:1251312522 .

Biber K, Laurie DJ, Berthele A, Sommer B, Tölle TR, Gebicke-Härter PJ, van Calker D, Boddeke HW (1999) Expression and signaling of group I metabotropic glutamate receptors in astrocytes and microglia. J Neurochem 72:1671-1680.

Borycz J, Pereira MF, Melani A, Rodrigues RJ, Köfalvi A, Panlilio L, Pedata F, Goldberg SR, Cunha RA, Ferré S (2007) Differential glutamate-dependent and glutamate-independent adenosine A1 receptor-mediated modulation of dopamine release in different striatal compartments. J Neurochem 101:355-363.

Bradley SJ, Challiss RA (2012) G protein-coupled receptor signalling in astrocytes in health and disease: a focus on metabotropic glutamate receptors. Biochem Pharmacol 84:249-259.

Calabresi P, Gubellini P, Centonze D, Sancesario G, Morello M, Giorgi M, Pisani A, Bernardi G (1999) A critical role of the nitric oxide/cGMP pathway in corticostriatal long-term depression. J Neurosci 19:2489-2499.

Cavaccini A, Gritti M, Giorgi A, Locarno A, Heck N, Migliarini S, Bertero A, Mereu M, Margiani G, Trusel M, Catelani T, Marotta R, De Luca MA, Caboche J, Gozzi A, Pasqualetti M, Tonini R (2018) Serotonergic signaling controls input-specific synaptic plasticity at striatal circuits. Neuron 98:801-816.e7.

Chai H, Diaz-Castro B, Shigetomi E, Monte E, Octeau JC, Yu X, Cohn W, Rajendran PS, Vondriska TM, Whitelegge JP, Coppola G, Khakh BS (2017) Neural circuit-specialized astrocytes: transcriptomic, proteomic, morphological, and functional evidence. Neuron 95:531-549.e9.

Chen J, Tan Z, Zeng L, Zhang X, He Y, Gao W, Wu X, Li Y, Bu B, Wang W, Duan S (2013) Heterosynaptic long-term depression mediated by ATP released from astrocytes. Glia 61:178-191.

Chepkova AN, Fleischer W, Kazmierczak T, Doreulee N, Haas HL, Sergeeva OA (2009) Developmental alterations of DHPG-induced long-term depression of corticostriatal synaptic transmission: switch from NMDA receptor-dependent towards CB1 receptor-dependent plasticity. Pflugers Arch 459:131-141.

Ciruela F, Casadó V, Rodrigues RJ, Luján R, Burgueño J, Canals M, Borycz J, Rebola N, Goldberg SR, Mallol J, Cortés A, Canela EI, López-Giménez JF, Milligan G, Lluis C, Cunha RA, Ferré S, Franco R (2006) Presynaptic control of striatal glutamatergic neurotransmission by adenosine A1A2A receptor heteromers. J Neurosci 26:2080-2087.

Covelo A, Araque A (2018) Neuronal activity determines distinct gliotransmitter release from a single astrocyte. Elife 7:e32237.

Cox J, Witten IB (2019) Striatal circuits for reward learning and decisionmaking. Nat Rev Neurosci 20:482-494.

Cui G, Jun SB, Jin X, Pham MD, Vogel SS, Lovinger DM, Costa RM (2013) Concurrent activation of striatal direct and indirect pathways during action initiation. Nature 494:238-242.

D’Ascenzo M, Fellin T, Terunuma M, Revilla-Sanchez R, Meaney DF, Auberson YP, Moss SJ, Haydon PG (2007) mGluR5 stimulates gliotransmission in the nucleus accumbens. Proc Natl Acad Sci USA 104:19952000.

Di Castro MA, Chuquet J, Liaudet N, Bhaukaurally K, Santello M, Bouvier D, Tiret P, Volterra A (2011) Local Ca2 + detection and modulation of synaptic release by astrocytes. Nat Neurosci 14:1276-1284.

Durkee CA, Araque A (2019) Diversity and specificity of astrocyte-neuron communication. Neuroscience 396:73-78.

Durkee CA, Covelo A, Lines J, Kofuji P, Aguilar J, Araque A (2019) G $\mathrm{G}_{\mathrm{i} / \mathrm{o}}$ protein-coupled receptors inhibit neurons but activate astrocytes and stimulate gliotransmission. Glia 67:1076-1093.

Fino E, Venance L (2010) Spike-timing dependent plasticity in the striatum. Front Synaptic Neurosci 2:6.

Fino E, Glowinski J, Venance L (2005) Bidirectional activity-dependent plasticity at corticostriatal synapses. J Neurosci 25:11279-11287.

Fredholm BB, Chen JF, Cunha RA, Svenningsson P, Vaugeois JM (2005) Adenosine and brain function. Int Rev Neurobiol 63:191-270.

Gerdeman GL, Ronesi J, Lovinger DM (2002) Postsynaptic endocannabinoid release is critical to long-term depression in the striatum. Nat Neurosci 5:446-451.

Gubellini P, Saulle E, Centonze D, Costa C, Tropepi D, Bernardi G, Conquet F, Calabresi P (2003) Corticostriatal LTP requires combined mGluR1 and mGluR5 activation. Neuropharmacology 44:8-16. 
Gundersen V, Storm-Mathisen J, Bergersen LH (2015) Neuroglial transmission. Physiol Rev 95:695-726.

Haustein MD, Kracun S, Lu X-H, Shih T, Jackson-Weaver O, Tong X, Xu J, Yang XW, O'Dell TJ, Marvin JS, Ellisman MH, Bushong EA, Looger LL, Khakh BS (2014) Conditions and constraints for astrocyte calcium signaling in the hippocampal mossy fiber pathway. Neuron 82:413-429.

Illes P, Burnstock G, Tang Y (2019) Astroglia-derived ATP modulates CNS neuronal circuits. Trends Neurosci 42:885-898.

Jiang R, Diaz-Castro B, Looger LL, Khakh BS (2016) Dysfunctional calcium and glutamate signaling in striatal astrocytes from Huntington's disease model mice. J Neurosci 36:3453-3470.

Khakh BS (2019) Astrocyte-neuron interactions in the striatum: insights on identity, form, and function. Trends Neurosci 42:617-630.

Kravitz AV, Tye LD, Kreitzer AC (2012) Distinct roles for direct and indirect pathway striatal neurons in reinforcement. Nat Neurosci 15:816-818.

Kreitzer AC, Malenka RC (2007) Endocannabinoid-mediated rescue of striatal LTD and motor deficits in Parkinson's disease models. Nature 445: 643-647.

Kreitzer AC, Malenka RC (2008) Striatal plasticity and basal ganglia circuit function. Neuron 60:543-554

Li X, Zima AV, Sheikh F, Blatter LA, Chen J (2005) Endothelin-1-induced arrhythmogenic $\mathrm{Ca} 2+$ signaling is abolished in atrial myocytes of inositol-1,4,5-trisphosphate(IP3)-receptor type 2-deficient mice. Circ Res 96:1274-1281.

Lovinger DM, Choi S (1995) Activation of adenosine A1 receptors initiates short-term synaptic depression in rat striatum. Neurosci Lett 199:9-12.

Lüscher C, Huber KM (2010) Group 1 mGluR-dependent synaptic longterm depression: mechanisms and implications for circuitry and disease. Neuron 65:445-459.

Manzoni OJ, Manabe T, Nicoll RA (1994) Release of adenosine by activation of NMDA receptors in the hippocampus. Science 265:2098-2101.

Martín R, Bajo-Graneras R, Moratalla R, Perea G, Araque A (2015) Circuitspecific signaling in astrocyte-neuron networks in basal ganglia pathways. Science 349:730-734.

Martin-Fernandez M, Jamison S, Robin LM, Zhao Z, Martin ED, Aguilar J, Benneyworth MA, Marsicano G, Araque A (2017) Synapse-specific astrocyte gating of amygdala-related behavior. Nat Neurosci 20:1540-1548.

Nakahara K, Okada M, Nakanishi S (1997) The metabotropic glutamate receptor mGluR5 induces calcium oscillations in cultured astrocytes via protein kinase C phosphorylation. J Neurochem 69:1467-1475.

Nazzaro C, Greco B, Cerovic M, Baxter P, Rubino T, Trusel M, Parolaro D, Tkatch T, Benfenati F, Pedarzani P, Tonini R (2012) SK channel modulation rescues striatal plasticity and control over habit in cannabinoid tolerance. Nat Neurosci 15:284-293.

O'Hare JK, Ade KK, Sukharnikova T, Van Hooser SD, Palmeri ML, Yin HH, Calakos N (2016) Pathway-specific striatal substrates for habitual behavior. Neuron 89:472-479.

Panatier A, Vallée J, Haber M, Murai KK, Lacaille JC, Robitaille R (2011) Astrocytes are endogenous regulators of basal transmission at central synapses. Cell 146:785-798.

Papouin T, Dunphy J, Tolman M, Foley JC, Haydon PG (2017) Astrocytic control of synaptic function. Philos Trans R Soc Lond B Biol Sci 372:20160154.

Pascual O, Casper KB, Kubera C, Zhang J, Revilla-Sanchez R, Sul JY, Takano H, Moss SJ, McCarthy K, Haydon PG (2005) Astrocytic purinergic signaling coordinates synaptic networks. Science 310:113-116.

Perea G, Araque A (2005) Glial calcium signaling and neuron-glia communication. Cell Calcium 38:375-382.

Porter JT, McCarthy KD (1996) Hippocampal astrocytes in situ respond to glutamate released from synaptic terminals. J Neurosci 16:5073-5081.
Rittiner JE, Caffall ZF, Hernández-Martinez R, Sanderson SM, Pearson JL, Tsukayama KK, Liu AY, Xiao C, Tracy S, Shipman MK, Hickey P, Johnson J, Scott B, Stacy M, Saunders-Pullman R, Bressman S, Simonyan K, Sharma N, Ozelius LJ, Cirulli ET, et al. (2016) Functional genomic analyses of mendelian and sporadic disease identify impaired eIF $2 \alpha$ signaling as a generalizable mechanism for dystonia. Neuron 92:1238-1251.

Savtchouk I, Volterra A (2018) Gliotransmission: beyond black-and-white. J Neurosci 38:14-25.

Serrano A, Haddjeri N, Lacaille JC, Robitaille R (2006) GABAergic network activation of glial cells underlies hippocampal heterosynaptic depression. J Neurosci 26:5370-5382.

Shen W, Flajolet M, Greengard P, Surmeier DJ (2008) Dichotomous dopaminergic control of striatal synaptic plasticity. Science 321:848-851.

Shigetomi E, Bowser DN, Sofroniew MV, Khakh BS (2008) Two forms of astrocyte calcium excitability have distinct effects on NMDA receptormediated slow inward currents in pyramidal neurons. J Neurosci 28:6659-6663.

Sippy T, Lapray D, Crochet S, Petersen CC (2015) Cell-type-specific sensorimotor processing in striatal projection neurons during goal-directed behavior. Neuron 88:298-305.

Spigolon G, Cavaccini A, Trusel M, Tonini R, Fisone G (2018) cJun N-terminal kinase (JNK) mediates cortico-striatal signaling in a model of Parkinson's disease. Neurobiol Dis 110:37-46.

Sun W, McConnell E, Pare JF, Xu Q, Chen M, Peng W, Lovatt D, Han X, Smith Y, Nedergaard M (2013) Glutamate-dependent neuroglial calcium signaling differs between young and adult brain. Science 339:197-200.

Sung KW, Choi S, Lovinger DM (2001) Activation of group I mGluRs is necessary for induction of long-term depression at striatal synapses. J Neurophysiol 86:2405-2412.

Tamura A, Yamada N, Yaguchi Y, Machida Y, Mori I, Osanai M (2014) Both neurons and astrocytes exhibited tetrodotoxin-resistant metabotropic glutamate receptor-dependent spontaneous slow $\mathrm{Ca} 2+$ oscillations in striatum. PLoS One 9:e85351.

Tecuapetla F, Matias S, Dugue GP, Mainen ZF, Costa RM (2014) Balanced activity in basal ganglia projection pathways is critical for contraversive movements. Nat Commun 5:4315.

Trusel M, Cavaccini A, Gritti M, Greco B, Saintot PP, Nazzaro C, Cerovic M, Morella I, Brambilla R, Tonini R (2015) Coordinated regulation of synaptic plasticity at striatopallidal and striatonigral neurons orchestrates motor control. Cell Rep 13:1353-1365.

Volterra A, Meldolesi J (2005) Astrocytes, from brain glue to communication elements: the revolution continues. Nat Rev Neurosci 6:626-640.

Wang X, Lou N, Xu Q, Tian GF, Peng WG, Han X, Kang J, Takano T, Nedergaard M (2006a) Astrocytic Ca2+ signaling evoked by sensory stimulation in vivo. Nat Neurosci 9:816-823.

Wang Z, Kai L, Day M, Ronesi J, Yin HH, Ding J, Tkatch T, Lovinger DM, Surmeier DJ (2006b) Dopaminergic control of corticostriatal long-term synaptic depression in medium spiny neurons is mediated by cholinergic interneurons. Neuron 50:443-452.

Wu YW, Kim JI, Tawfik VL, Lalchandani RR, Scherrer G, Ding JB (2015) Input- and cell-type-specific endocannabinoid-dependent LTD in the striatum. Cell Rep 10:75-87.

Yin HH, Adermark L, Lovinger DM (2008) Neurotensin reduces glutamatergic transmission in the dorsolateral striatum via retrograde endocannabinoid signaling. Neuropharmacology 54:79-86.

Zhang JM, Wang HK, Ye CQ, Ge W, Chen Y, Jiang ZL, Wu CP, Poo MM, Duan S (2003) ATP released by astrocytes mediates glutamatergic activity-dependent heterosynaptic suppression. Neuron 40:971-982. 